\title{
GPS constraints on deformation in northern Central America from 1999 to 2017, Part 2: Block rotations and fault slip rates, fault locking and distributed deformation
}

\author{
A. Ellis,${ }^{1}$ C. DeMets ${ }^{\oplus},{ }_{1}^{1}$ Robert McCaffrey, ${ }^{2}$ P. Briole, ${ }^{3}$ Beatriz Cosenza Muralles ${ }^{1}$, \\ Omar Flores, ${ }^{4}$ Marco Guzmán-Speziale, ${ }^{5}$ Douglas Hernández, ${ }^{6}$ Vladimir Kostoglodov, ${ }^{7}$ \\ Peter LaFemina ${ }^{8}$ Neal Lord, ${ }^{1}$ Cécile Lasserre ${ }^{\oplus},{ }^{9}$ Hélène Lyon-Caen, ${ }^{3}$ Manuel Rodriguez \\ Maradiaga, ${ }^{10}$ Enrique Molina, ${ }^{11}$ Jeffrey Rivera, ${ }^{11}$ Robert Rogers, ${ }^{12}$ Alejandra Staller ${ }^{\oplus 13}$ \\ and Basil Tikoff ${ }^{1}$ \\ ${ }_{1}^{1}$ Department of Geoscience, University of Wisconsin-Madison, Madison, WI 53706, USA. E-mail: chuck@geology.wisc.edu \\ ${ }^{2}$ Department of Geology, Portland State University, Portland, OR, 97207, USA \\ ${ }^{3}$ Laboratoire de Géologie, de l'Ecole Normale Supérieure, UMR8538 of CNRS, Paris, France \\ ${ }^{4}$ Departamento de Fisica Ingenieria, Universidad San Carlos, Guatemala City, Guatemala \\ ${ }^{5}$ Centro de Geociencias, Universidad Nacional Autónoma de México, Blvd. Juriquilla 3001, Querétaro 76230, Mexico \\ ${ }^{6}$ Ministerio de Medio Ambiente y Recursos Naturales, Km. 5 1/2 carretera a Santa Tecla, Colonia y Calle Las Mercedes, Plantel ISTA, San Salvador, El \\ Salvador \\ ${ }^{7}$ Instituto de Geofisica, Universidad Nacional Autónoma de México, Mexico City, Mexico \\ ${ }^{8}$ Department of Geosciences, Pennsylvania State University, University Park, PA 16802, USA \\ ${ }^{9}$ ISTerre, CNRS, Université Grenoble-Alpes, BP53, 38041 Grenoble Cedex 9, France \\ ${ }^{10}$ Instituto Hondureño de Ciencias de la Tierra, Universidad Nacional Autónoma de Honduras, Tegucigalpa, Honduras \\ ${ }^{11}$ Department of Civil Engineering, Universidad Mariano Galvez, Guatemala City, Guatemala \\ ${ }^{12}$ Department of Geology, California State University Stanislaus, Turlock, California, USA \\ ${ }^{13}$ Dpto. de Ingeniería Topográfica y Cartografia, Universidad Politécnica de Madrid, Madrid, Spain
}

\section{SUMMAR Y}

We describe a new elastic-kinematic model for the present tectonics of northern Central America and southern Mexico, where the Motagua-Polochic fault zone, Middle America subduction zone and faults in the Central America volcanic arc pose significant seismic hazards. The new model, which consists of the angular velocities for eight plates and blocks, interseismic locking solutions for some of the block-bounding faults and strain-rate tensors for three blocks with significant internal deformation, optimizes the fit to regional fault azimuths and earthquake slip directions and a new 200+ station GPS velocity field that has been corrected for the coseismic and post-seismic effects of three large regional earthquakes in 2009 and 2012. From our new observations and modelling thereof, we find evidence for the following: (1) $13 \pm 1 \mathrm{~mm} \mathrm{yr}^{-1}$ of $\approx \mathrm{E}-\mathrm{W}$ stretching between undeformed Caribbean plate in central Honduras and a location $\approx 50 \mathrm{~km}$ west of the Guatemala City graben; (2) accommodation of the above extension via slow W-to-WNW motions of newly defined Chortis and Ipala blocks and distributed ENE-WSW stretching within both blocks; (3) 80 per cent of Chortis-North America plate motion in eastern Guatemala occurs on the Motagua fault versus only 20 per cent on the Polochic fault; (4) Motagua fault slip rates that decrease westwards from $14 \pm 1.5 \mathrm{~mm}$ $\mathrm{yr}^{-1}$ to $9-10 \pm 2 \mathrm{~mm} \mathrm{yr}^{-1}$ to less than $2 \mathrm{~mm} \mathrm{yr}^{-1}$ in eastern Guatemala, central Guatemala and west of the Guatemala City graben, respectively; (5) Slip rates along Central America volcanic arc faults that decrease from $12.5 \pm 1.0 \mathrm{~mm} \mathrm{yr}^{-1}$ in Nicaragua to $10 \pm 1.3 \mathrm{~mm} \mathrm{yr}^{-1}$ in central El Salvador to $7.6 \pm 2.1 \mathrm{~mm} \mathrm{yr}^{-1}$ on the Jalpatagua fault of southern Guatemala to $2-3 \mathrm{~mm} \mathrm{yr}^{-1}$ or less across the volcanic arc west of Guatemala City; (6) a transition near the Mexico-Guatemala border from moderate-to-high locking of the subduction interface offshore from southern Mexico to low locking below the Central America forearc sliver; (7) Subduction of the Cocos plate beneath the Central America forearc sliver up to $10 \mathrm{~mm} \mathrm{yr}^{-1}$ faster than and 7-8 clockwise from all previous estimates; (8) $12 \pm 6 \mathrm{~mm} \mathrm{yr}^{-1}$ of E-W 
extension across the newly defined Fonseca block. A pattern of misfits to the velocities of sites in northern Guatemala and southern Mexico may be caused by distributed deformation in this region or shortcomings with our model and/or assumptions. The primary factors that control the regional deformation appear to include the arcuate geometry of the Motagua fault, low locking of the Middle America subduction interface, slow-to-no motion between the leading edge of the Central America forearc sliver and North America plate and a rheologically weak volcanic arc.

Key words: seismic cycle; space geodetic surveys; plate motions; earthquake hazards; continental neotectonics.

\section{INTRODUCTION}

Geodetic studies in northern Central America and adjoining areas of southern Mexico began in the late 1990s, with specific goals of estimating slip rates for the region's numerous seismically hazardous faults and a broad objective of understanding deformation at the western end of the Caribbean plate, where sinistral motion between the Caribbean and North America plates and dextral shear along the Central America volcanic arc both terminate in a poorly understood region of diffuse continental deformation (Fig. 1). Plafker (1976) first outlined the principal elements of a tectonic framework for this region, consisting of sinistral slip along the Motagua-Polochic fault zone, east-west extension in areas of Guatemala and Honduras south of the Motagua fault and a rheologically weak Central America volcanic arc. Notable later modifications of Plafker's tectonic framework include trenchparallel, northwest translation of a Central America forearc sliver along faults in the Central America volcanic arc (Harlow \& White 1985; White \& Harlow 1993; White et al. 2004), distributed deformation in the Chiapas Tectonic Province and areas of Guatemala north of the Polochic fault (Guzman-Speziale et al. 1989; GuzmanSpeziale 2010) and lateral, trench-parallel escape of the Central America forearc sliver from the collision between the oceanic Cocos Ridge and western Costa Rica (LaFemina et al. 2009; Kobayashi et al. 2014).

Campaign and continuous GPS measurements in Central America since the late 1990s have corroborated major elements of the above tectonic framework. From measurements at 16 campaign GPS sites in Guatemala, Lyon-Caen et al. (2006) found that the Motagua and Polochic faults accommodate nearly all Caribbean-North America plate motion, including evidence for a previously unknown decrease in the Motagua fault slip rate westwards along the fault. From the velocities of 37 GPS sites in Honduras, Rodriguez et al. (2009) find that sites in western Honduras move $4 \pm 1 \mathrm{~mm} \mathrm{yr}^{-1}$ west to west-northwest away from sites in eastern Honduras, confirming structural and seismic evidence for active extension south of the Motagua fault. From finite element modelling of 32 GPS site velocities in El Salvador and Nicaragua, Correa-Mora et al. (2009) propose that locking of the Middle America subduction interface offshore from El Salvador averages no more than a few per cent of the plate convergence rate, but infer high locking of the seismically hazardous strike-slip faults in the volcanic arc of El Salvador. Elastic half-space modelling by Franco et al. (2012) of the velocities of 40 GPS sites in northern Central America and southern Mexico confirms that the Motagua fault slip rate decreases from east to west, that faults in the Guatemalan volcanic arc accommodate dextral slip as fast as $\approx 15 \mathrm{~mm} \mathrm{yr}^{-1}$ and that locking on the Middle America subduction interface transitions from moderate-to-high offshore southern Mexico to low off the coast of southern Guatemala.

Herein, we describe and invert newly determined interseismic velocities for 201 GPS sites in northern Central America and southern Mexico along with fault azimuths and earthquake slip directions to quantify the long-term and interseismic regional deformation with more precision and in more detail than was previously possible. This is the second stage of a two-part seismotectonic study of northern Central America that is based on the many new geodetic data that have become available since the Franco et al. (2012) regional-scale geodetic study of northern Central America. In the first stage of our analysis, Ellis et al. (2018) inverted the daily position time-series for more than 200 regional GPS sites to estimate time-dependent coseismic slip and post-seismic afterslip solutions for the 2009 May $M_{\mathrm{w}}=7.3$ Swan Islands, 2012 August $M_{\mathrm{w}}=$ 7.3 El Salvador and 2012 November $M_{\mathrm{w}}=7.4$ Guatemala (Champerico) earthquakes (Fig. 2), which collectively altered the post2009 motions of most GPS stations in northern Central America. Ellis et al. also determined interseismic velocities for all $200+$ GPS sites from inversions of their position time-series suitably corrected for the time- and location-dependent coseismic and afterslip effects of all three earthquakes. These interseismic velocities, which are described for the first time herein, constitute most of the basis for this analysis.

From these new velocities and other data, we estimate angular velocities for eight elastic plates or blocks, interseismic locking along the block-bounding faults, and strain-rate tensors for three blocks that deform internally. The new model, which also satisfies several a priori geologically based constraints and meets closure requirements for the angular velocities, constitutes an internally consistent, elastic-kinematic description of the interseismic and long-term deformation of our study area. Important topics that are treated herein include (1) the most complete description to date of distributed deformation within the 450-km-wide, triangular-shaped Chortis extensional zone between the Motagua fault and Central America volcanic arc, including first estimates of angular velocities and internal strain rates for the newly defined Chortis and Ipala blocks and opening rate and opening direction estimates for the Ipala and Guatemala City grabens of southern Guatemala (Fig. 1). (2) A first angular velocity estimate for Cocos plate motion relative to the Central America forearc sliver. (3) Estimates of slip rates along all $900 \mathrm{~km}$ of volcanic arc faults between Nicaragua and southern Mexico, including a first estimate for the little studied Jalpatagua fault of southern Guatemala. (4) Estimates of the average interseismic locking for the subduction interface offshore southernmost Mexico and beneath the Central America forearc sliver. (5) Well-constrained estimates of slip rates for the Motagua and Polochic faults. 


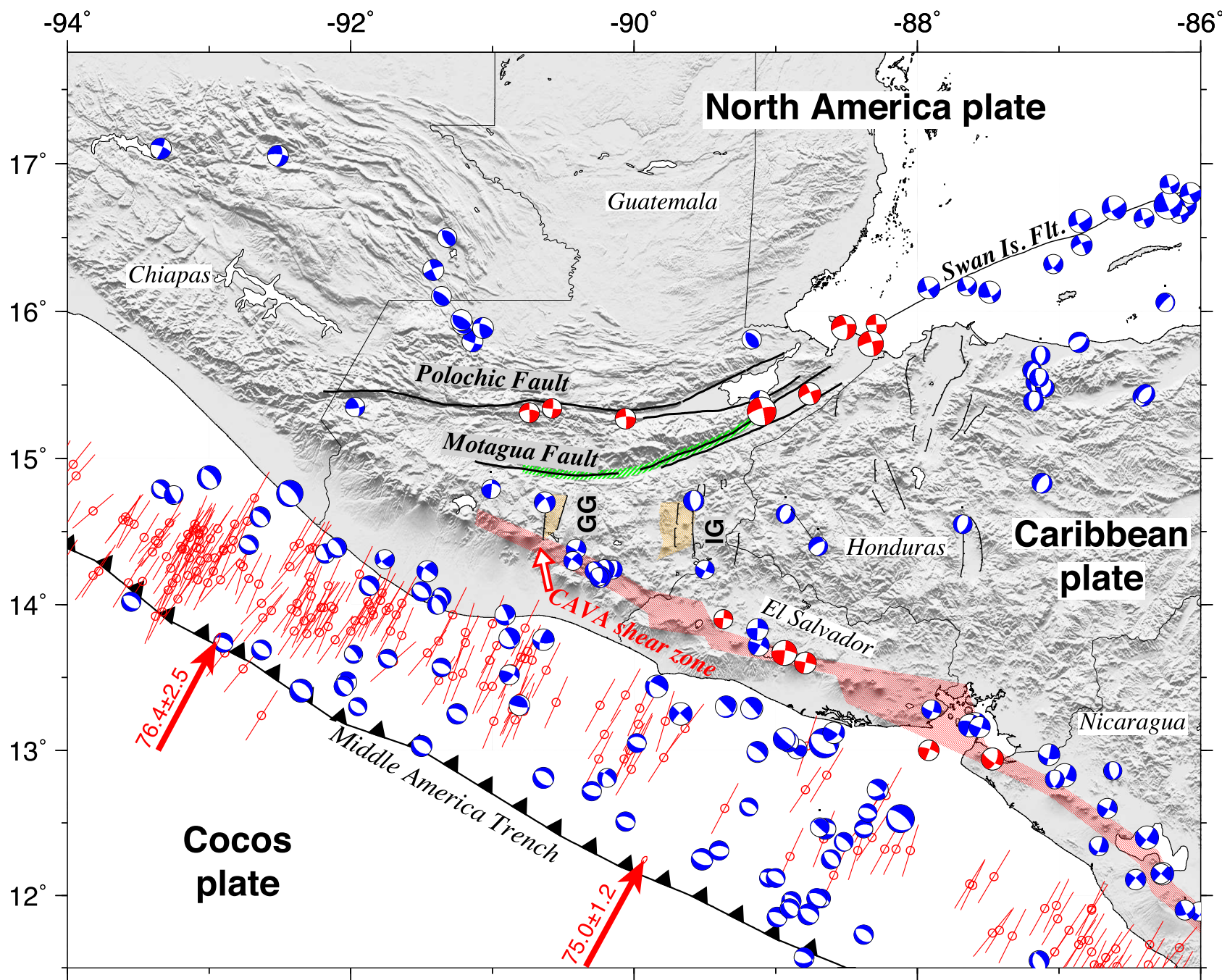

Figure 1. Topography and earthquake focal mechanisms in northern Central America. Focal mechanisms include all global centroid-moment tensor solutions for 1976 to mid-2016, and pre-1976 focal mechanisms from Molnar \& Sykes (1969), Guzman-Speziale (2010) and White \& Harlow (1993). The narrow green-patterned region shows the rupture limits of the $1976 M_{\mathrm{w}}=7.5$ Motagua Fault earthquake. The orange-shaded regions show locations of the Guatemala City graben (GG) and Ipala graben (IG). Red focal mechanisms were used to constrain the regional block motions (Section 2.2). For clarity, the offshore focal mechanisms are limited to normal-faulting and strike-slip earthquakes. The information about the offshore subduction-thrust earthquakes that were used to constrain our block model is limited to the P-axis orientation for each earthquake (red line). The red velocity arrows show Cocos Plate velocities relative to the Central America forearc sliver as estimated in this study. The units are in $\mathrm{mm} \mathrm{yr}^{-1}$ for the velocities and their $1-\sigma$ uncertainties. The pink region labelled 'CAVA shear zone' outlines the Central America volcanic arc (CAVA) detachment zone between the forearc sliver and areas inland from the arc.

\section{DATA}

\subsection{Raw geodetic data and processing}

For our two-part study, we compiled all available legacy and new GPS data from El Salvador, Guatemala, Honduras, parts of Nicaragua and the Mexican state of Chiapas. These included all the raw GPS data that were used to derive previous velocity fields, which span the period 1999 to 2012 (Lyon-Caen et al. 2006; Turner et al. 2007; Correa-Mora et al. 2009; LaFemina et al. 2009; Rodriguez et al. 2009; Alvarado et al. 2011; Franco et al. 2012; Staller et al. 2016). New observations from our own field efforts come from the following sources: (1) Seven continuous GPS stations that we installed in southern Guatemala and western El Salvador in 2012 and 2014. (2) 14 new and 18 pre-existing campaign sites in Guatemala that we occupied one or more times between 2012 and 2017. (3) Three new and 22 pre-existing campaign sites that we occupied one or more times in Honduras since 2012. (4) Five preexisting campaign sites in El Salvador. New data from other sources consist of continuous data from a 12-station national network that was installed in 2010 by Guatemala's Instituto Geografico Nacional and continuous data for sites archived at UNAVCO (unavco.org) and the National Geodetic Survey (geodesy.noaa.gov/CORS).

Overall, we use data from more than 200 stations (Fig. 2), of which roughly one-third are continuous and the rest campaign. Supporting Information Table S1 gives the locations, velocities and other relevant information for these sites. Other useful information, including the data sources for all the GPS sites, can be found in Ellis et al. (2018) and their Supporting Information.

Ellis et al. (2018) describe the methods that we use to process all the raw GPS data for our two-stage analysis, and the corrections to all the GPS station position time-series for the coseismic and postseismic effects of the earthquakes in 2009 and 2012. Supporting Information Table $\mathrm{S} 1$ gives the horizontal velocities of all $200+$ GPS 


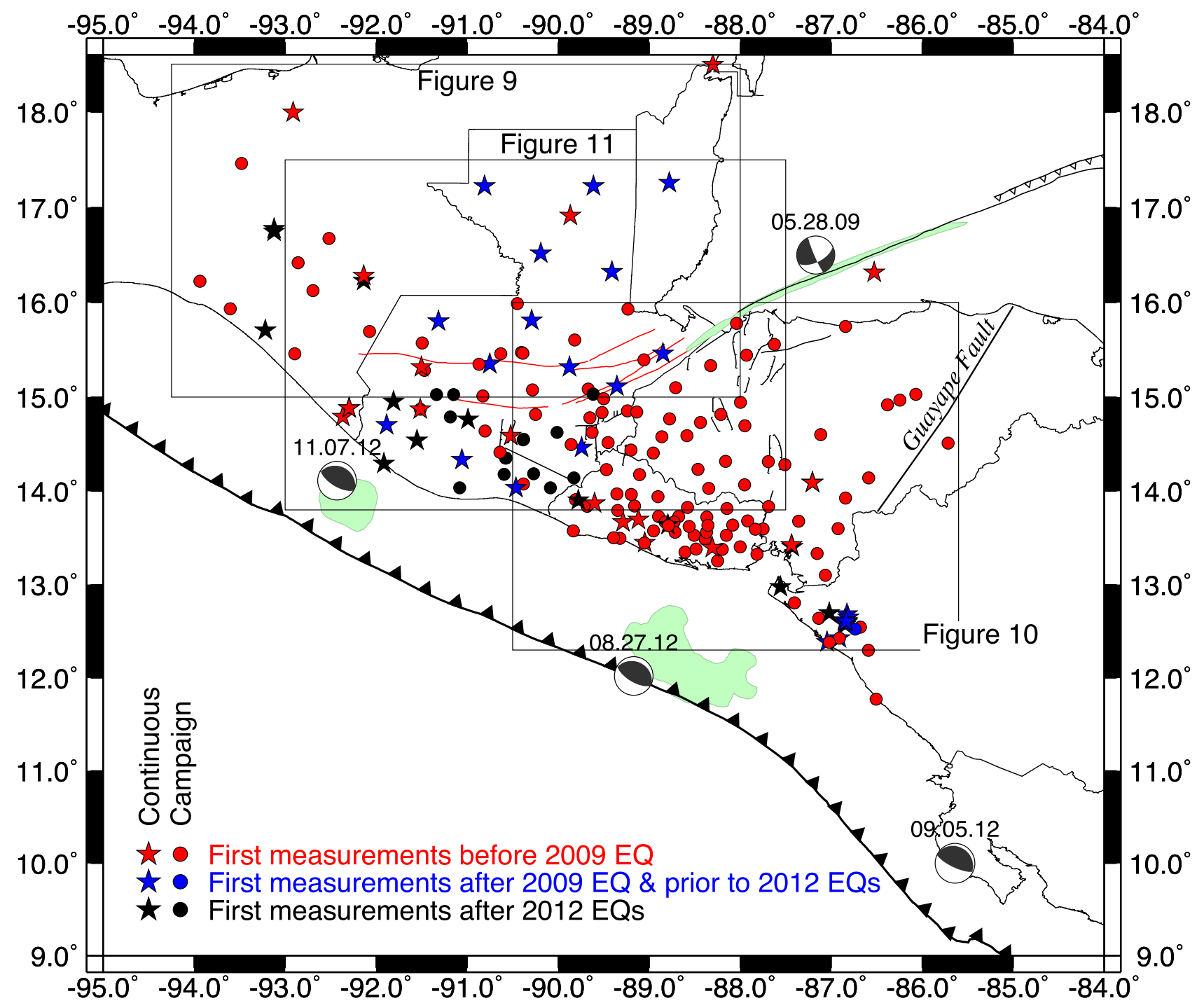

Figure 2. Locations of GPS stations used in this study. The velocities of all GPS sites used in this study were corrected by Ellis et al. (2018) for the transient effects of the three post-2009 earthquakes whose rupture areas are depicted by the light green patches in the figure. EQ; earthquake. This figure is adapted from Ellis et al. (2018). The boxes identify regions that are shown in later figures.

sites in our study area relative to the IGS08 reference frame, whose site velocities conform with the International Terrestrial Reference Frame 2008 (Altamimi et al. 2011). Vertical GPS site rates were not used for our analysis since the rates at most sites were zero within their uncertainties.

\subsection{GPS site velocities relative to the Caribbean and North America plates}

The Caribbean and North America plates, which are the natural geological frames of reference for tectonic studies in the western Caribbean and Central America, are used herein as a basis for interpreting our station velocities and as a priori far-field constraints on the regional plate motions for all the inversions described below and in the Supporting Information. We inverted the velocities of 11 continuous and campaign sites in nominally undeforming areas of the Caribbean plate interior (Supporting Information Fig.1a and the Supporting Information Table S2) and 989 North America plate continuous GPS sites (Supporting Information Fig.1b and the Supporting Information Table S3) to determine best-fitting angular velocities for both plates relative to ITRF08 and relative to each other (Table 1). The weighted root-mean-square (WRMS) misfits of the best-fitting angular velocities are 0.66 and $0.78 \mathrm{~mm} \mathrm{yr}^{-1}$ for the north- and east-velocity components of the 11 Caribbean plate sites and $0.44 \mathrm{~mm} \mathrm{yr}^{-1}$ (north) and $0.40 \mathrm{~mm} \mathrm{yr}^{-1}$ (east) for the 989 North America plate sites. The larger misfits to the Caribbean plate site velocities may be attributable to their heterogeneous mix of campaign and continuous sites and the proximity of most of the sites to the Caribbean plate boundaries, where the sites may be affected by interseismic elastic deformation, postseismic viscoelastic deformation and/or distributed plate boundary deformation.

Near the centre of our study area $\left(14.5^{\circ} \mathrm{N}, 89^{\circ} \mathrm{W}\right)$, our newly estimated Caribbean-North America plate angular velocity (Table 1) predicts that the Caribbean plate moves $19.0 \pm 0.2 \mathrm{~mm} \mathrm{yr}^{-1}$ towards $\mathrm{N} 74.9^{\circ} \mathrm{E} \pm 1^{\circ}$ ( 95 per cent limits) relative to North America. Previously published Caribbean-North America angular velocities predict velocities of $19.4 \mathrm{~mm} \mathrm{yr}^{-1}$ towards $\mathrm{N} 75.5^{\circ} \mathrm{E}$ (DeMets et al. 2007), $20.1 \mathrm{~mm} \mathrm{yr}^{-1}$ towards $\mathrm{N} 73.9^{\circ} \mathrm{E}$ (Benford et al. 2012) and $17.7 \mathrm{~mm} \mathrm{yr}^{-1}$ towards $\mathrm{N} 76.0^{\circ} \mathrm{E}$ (Symithe et al. 2015) at the same 
Table 1. Best-fitting angular velocities.

\begin{tabular}{|c|c|c|c|c|c|c|c|c|c|c|c|c|c|}
\hline $\begin{array}{l}\text { Moving } \\
\text { plate }\end{array}$ & $\begin{array}{l}\text { Fixed } \\
\text { plate }\end{array}$ & $\begin{array}{l}\text { Lat. } \\
\left({ }^{\circ} \mathrm{N}\right)\end{array}$ & $\begin{array}{l}\text { Long. } \\
\left({ }^{\circ} \mathrm{E}\right)\end{array}$ & $\begin{array}{c}\dot{\omega} \\
\left({ }^{\circ} \mathrm{Myr}^{-1}\right)\end{array}$ & \multicolumn{6}{|c|}{ Variances and covariances } & $\sigma_{x y}$ & $\sigma_{x z}$ & $\sigma_{y z}$ \\
\hline NOAM & ITRF08 & -6.9 & 271.4 & 0.184 & 0.0046 & -0.1824 & -0.0220 & 0.00001 & 0.00042 & 0.00023 & -0.00001 & 0.00001 & -0.00030 \\
\hline CARI & NOAM & 74.8 & 201.0 & 0.181 & -0.0442 & -0.0170 & 0.1747 & 0.00266 & 0.03540 & 0.00393 & -0.00742 & 0.00209 & -0.00982 \\
\hline $\mathrm{COCO}$ & NOAM & 31.0 & 226.3 & 1.073 & -0.6354 & -0.6649 & 0.5526 & 0.34 & 0.48 & 0.39 & -0.05 & -0.28 & -0.08 \\
\hline $\mathrm{COCO}$ & CAFS & -21.6 & -27.6 & -0.718 & -0.5913 & 0.3091 & 0.2641 & 0.08 & 84.33 & 4.29 & -1.10 & 0.20 & -18.90 \\
\hline CHRT & NOAM & 68.2 & 158.7 & 0.156 & -0.0539 & 0.0210 & 0.1447 & 0.03 & 17.88 & 1.28 & -0.40 & 0.10 & -4.70 \\
\hline CHRT & IPALA & 11.1 & -87.2 & -0.549 & -0.0262 & 0.5376 & -0.1060 & 0.10 & 637.76 & 45.07 & 2.30 & -0.60 & -169.00 \\
\hline CHRT & CAFS & 8.2 & -89.4 & -1.006 & -0.0098 & 0.9954 & -0.1436 & 0.11 & 102.21 & 5.58 & -1.50 & 0.30 & -23.60 \\
\hline CHRT & FONS & 18.5 & -87.3 & 0.473 & 0.0214 & -0.4481 & 0.1502 & 20.39 & 17101.50 & 988.04 & -588.50 & 141.40 & -4109.90 \\
\hline CHRT & MOPO & -23.6 & -73.2 & -0.187 & -0.0495 & 0.1642 & 0.0750 & 0.04 & 31.47 & 2.86 & -0.40 & 0.10 & -9.20 \\
\hline CAFS & CARI & 6.8 & -90.0 & 0.964 & 0.0002 & -0.9573 & 0.1134 & 0.08 & 84.33 & 4.29 & -1.10 & 0.20 & -18.90 \\
\hline
\end{tabular}

The Cocos-Caribbean angular velocity is the MORVEL estimate from DeMets et al. (2010). The angular rotation rate $\dot{\omega}$ is positive anticlockwise. The Cartesian angular velocity components

$\dot{\omega}_{x}, \dot{\omega}_{y}$ and $\dot{\omega_{z}}$ have units of degrees per Myr. The angular velocity covariances are Cartesian and have units of $10^{-4}$ degrees $^{2} \mathrm{Myr}^{-2}$. Abbreviations are as follows:

CAFS, Central America forearc sliver; CARI, Caribbean plate; CHRT, Chortis block; COCO, Cocos plate; FONS, Fonseca block; ITRF08, International Terrestrial Reference Frame 2008; MOPO, Motagua-Polochic block; NOAM, North America plate.

location. Our newly determined angular velocity thus predicts a velocity near the midpoint of previous estimates.

Fig. 3shows the observed GPS site velocities from Supporting Information Table S1 after transforming them to the Caribbean plate reference frame with the Caribbean-ITRF08 angular velocity from Table 1 . The velocity field reveals prominent gradients across the Motagua-Polochic fault zone, which cross-cuts the entire GPS network, and the Central America volcanic arc along the Pacific coast. Several important aspects of the velocity field that are less obvious in Fig. 3due to the frame of reference and/or scale of the plot include inland-directed elastic shortening in southern Mexico due to locking of the offshore subduction interface and distributed extension in Honduras and southern Guatemala.

Six figures and their accompanying text are included in our Supporting Information in order to display and describe the velocity gradients across the major fault zones in our study area and alongstrike changes in those velocity gradients, which are important to this analysis. Specifically, Supporting Information Fig. S2 shows the regional velocity field relative to the North America plate, which offers a useful alternative perspective to the Caribbean-fixed velocity field in Fig. 3. Supporting Information Fig. S4 compares the trench-normal components of the GPS site velocities for trenchnormal transects in southern Mexico and Central America. Supporting Information Figs S5 and S6 show four transects of the GPS velocity field across the Motagua-Polochic fault zone and Supporting Information Figs S7 and S8 show six velocity field transects of the 900-km-long Central America volcanic arc. Several figures include predictions from simple 1-D forward elastic models, which facilitate basic interpretations of the velocities and reinforce the 2-D elastic block modelling results that are described below.

\subsection{Seismic and fault data}

We also use $\approx 200$ horizontal slip directions from a subset of the focal mechanisms in the global centroid-moment tensor catalogue (Dziewonski et al. 1981; Ekström et al. 2012) to constrain the regional fault and block motions. These include eight strike-slip earthquakes along the Motagua and Polochic faults, three strike-slip earthquakes along the volcanic arc in El Salvador and two strikeslip earthquakes in and offshore from northwestern Nicaragua. Fig. 1shows the locations and focal mechanisms for all 13 earthquakes and information about all 13 earthquakes can be found in the Supporting Information Table S4. Although numerous other strike-slip earthquakes occur along the Central American volcanic arc (bluecoloured focal mechanisms in Fig. 1), we selected only those earthquakes from strike-slip faults that unambiguously accommodate dextral, arc-parallel movement of the forearc sliver relative to areas inland from the arc. We did not use earthquakes from the Nicaraguan volcanic arc, where bookshelf faulting is pervasive (LaFemina et al. 2002; Funk et al. 2009), nor did we use earthquakes from extensional step-overs in the volcanic arc of El Salvador, where distributed normal and bookshelf faulting occur (e.g. Corti et al. 2005; Agostini et al. 2006).

We also extracted horizontal slip directions for 276 reversefaulting earthquakes from the Middle America trench offshore from our study area (Fig. 4and the Supporting Information Fig. S3). Offshore from Guatemala, El Salvador and Nicaragua, an $\approx 8^{\circ}$ clockwise bias of the earthquake slip directions relative to the convergence direction that is predicted by the MORVEL Cocos-Caribbean plate angular velocity (compare blue line to grey circles in Fig. 4) offers clear evidence for northwestward movement of the Central America forearc sliver relative to the Caribbean plate interior. The slip directions for all 188 subduction-thrust earthquakes that occurred east of $93.5^{\circ} \mathrm{W}$ are used in the inversion described below to 


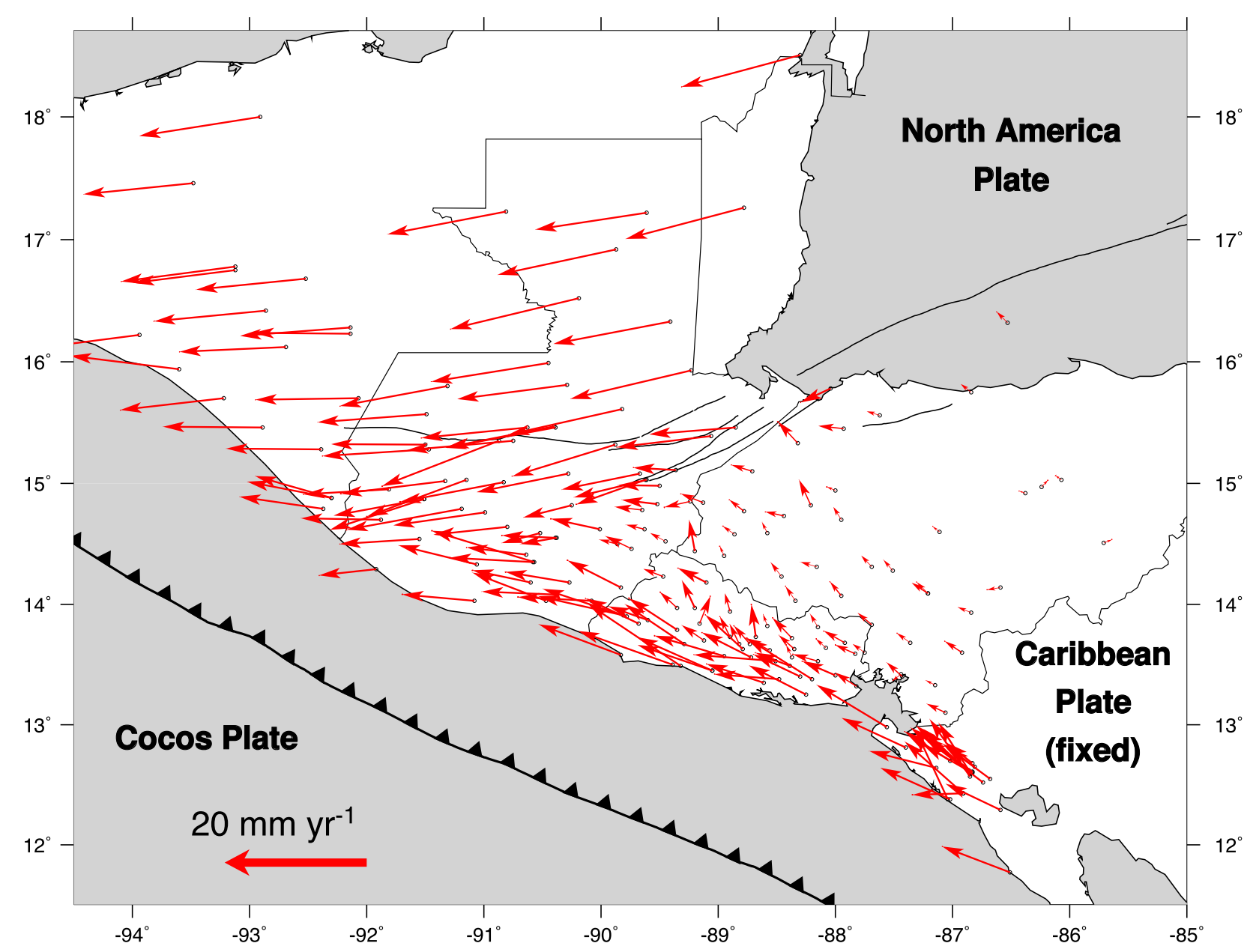

Figure 3. GPS site velocities relative to the Caribbean Plate corrected for coseismic offsets and transient afterslip from the 2009 Swan Islands earthquake and the 2012 El Salvador and southern Guatemala earthquakes (Ellis et al. 2018). Supporting Information Fig. S2 shows the site motions relative to a fixed North America plate. The velocity error ellipses, which are omitted here for clarity, are displayed in subsequent figures.

help constrain the direction of Cocos plate subduction beneath the Central America forearc sliver (Fig. 4and the Supporting Information Table S4).

We also use the azimuths of several strike-slip faults to constrain the local directions of relative plate/block motion in our model (Supporting Information Table S4). We measured the azimuth of the Motagua fault at eight locations where its location and orientation are easily identified from topography. Along the Central America volcanic arc, five major strike-slip fault segments are apparent in the topography and described in the literature, namely the San Miguel, Berlin, Lempa and San Vicente faults in El Salvador and Jalpatagua fault in southern Guatemala. Of these, we use the azimuths of the San Vicente, Berlin and San Miguel fault segments in central and eastern El Salvador to constrain our block model. The San Vicente fault accommodates movement between the forearc sliver and Chortis block (Corti et al. 2005; Canora et al. 2014), whereas the San Miguel and Berlin faults accommodate slip between the Fonseca and Chortis blocks. We exclude the Lempa fault of central El Salvador, which borders an actively deforming, volcanic arc pull-apart zone that is not included in our block model. We exclude the Jalpatagua fault of southeastern Guatemala (Carr 1976; Wunderman \& Rose 1984; Authemayou et al. 2011) because of evidence that the motion between the blocks that are separated by this fault is partitioned between strike-slip motion on the Jalpatagua fault and normal faulting to the south (see Section 4.7.5).

\section{MODELLING APPROACH, ASSUMPTIONS AND INVERSION STRATEG Y}

\subsection{TDEFNODE}

We use TDEFNODE (McCaffrey 2002, 2009) to estimate a bestfitting, elastic-kinematic model for the 201 GPS site velocities and other data and constraints described in Section 2. The parameters that are estimated in our TDEFNODE model include angular velocities that describe the long-term motions of the elastically deforming plates or blocks that comprise the model, interseismic locking ratios for most of the block-bounding faults, strain-rate tensors that describe the long-term distributed deformation within some blocks, and locking depths for several strike-slip faults. The fault locking ratio is defined as the fractional part of the relative plate or block motion that is not accommodated by steady aseismic slip on a fault (McCaffrey 2002). Our best-fitting solution minimizes the reduced chi-square statistic $\chi^{2}{ }_{v}$ (i.e. the weighted least-squares misfit $\chi^{2}$ normalized by the degrees of freedom) subject to a variety of smoothing and a priori constraints that are imposed during the 


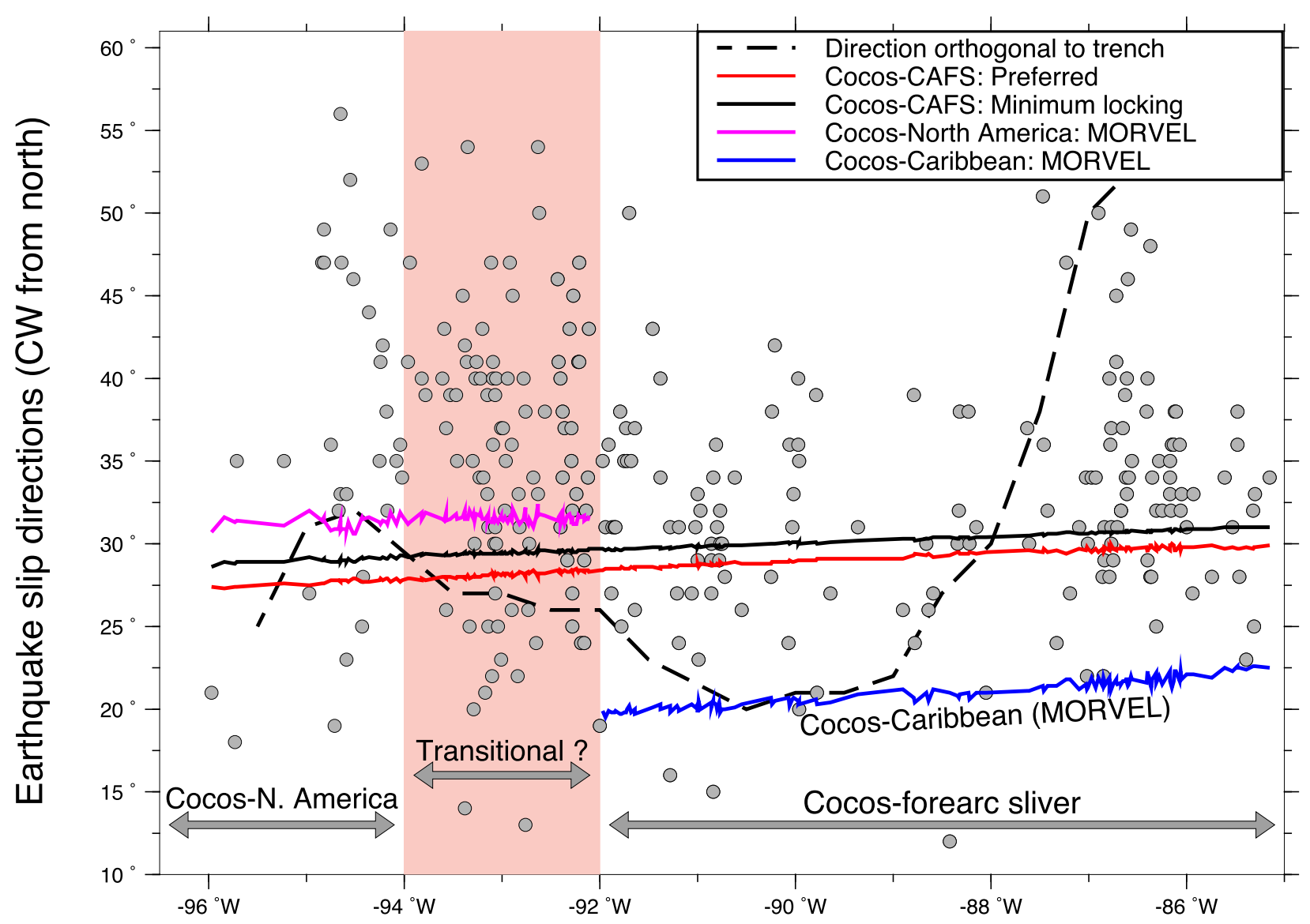

Figure 4. Horizontal slip directions (circles) for Middle America trench shallow thrust-faulting earthquakes shown in Supporting Information Fig. S3 versus the directions (lines) of Cocos plate convergence relative to the overlying plate, where the overlying plate is variously assumed to be the Central America forearc sliver or the North America or Caribbean plates. The black and red lines indicate the preferred and minimum-locking model estimates that are variously described in the text and the Supporting Information. The dashed black line shows the direction that is locally orthogonal to the trench.

inversion. Formal uncertainties in the model parameters are propagated from the observations and are based on the assumption that the data errors are random. Readers are referred to McCaffrey (2002) and McCaffrey (2009) for further information about TDEFNODE and its predecessor DEFNODE.

Other TDEFNODE outputs that are used or displayed herein include the following: (1) GPS site velocities estimated with the bestfitting model(s), (2) residual GPS site velocities, which are defined as the modelled velocity subtracted from the observed velocity, (3) the long-term component of each modelled site velocity, which is determined from the angular velocity for the block that is associated with the site and, if relevant, the strain-rate tensor estimated for the block, (4) the elastic-only component of each modelled GPS site velocity, which isolates the elastic effects of all locked faults within the model, (5) weighted root-mean-square (WRMS) values for the velocity misfits for the GPS sites on each plate or block in the model and (6) long-term slip rates for all the block-bounding faults, which are estimated from the relative angular velocity for the two blocks that bound the fault and any relevant strain-rate tensors for the bounding blocks.

\subsection{Assumed plate and block geometries}

Based on geological, geodetic and seismological evidence, we used our new velocity field to test block configurations for northern Central America with up to 10 tectonic blocks or plates. Fig. 5shows the geometry of the plates and blocks in our study area, including the well-defined Cocos, North America and Caribbean plates and a northwest-translating Central America forearc sliver with lateral boundaries at the Middle America trench and Central America volcanic arc (light blue in Fig. 5). The leading and trailing edges of the forearc sliver are approximated with free-slip boundaries (e.g. no fault locking) to avoid possible elastic effects from these two poorly understood and probably diffuse boundaries. An elongate Motagua-Polochic block, which is bounded by the Motagua and Polochic faults (Fig. 5), is included to estimate separate slip rates for the two faults. The Fonseca block encompasses the $\approx 120$-kmwide Gulf of Fonseca step-over in the Central America volcanic arc, where geodetic, paleomagnetic, seismic and structural observations define a region of active deformation that includes the Gulf of Fonseca and adjacent areas of eastern El Salvador (Funk et al. 2009; Alvarado et al. 2011).

The appropriate block geometry is less obvious for the deforming triangular region between the Motagua fault and volcanic arc (Fig. 5), where $\approx \mathrm{N}-\mathrm{S}$ trending grabens that include the Guatemala City and Ipala grabens (Weyl 1980; Rogers \& Mann 2007), normal faulting earthquakes (Guzman-Speziale 2001; Caceres et al. 2005 and Fig. 1) and scattered seismicity are all consistent with widely distributed $\approx \mathrm{E}-\mathrm{W}$ extension (Fig. 1). From geologic mapping and seismicity, Gordon \& Muehlberger (1994) propose that a deforming Chortis block occupies this entire region, bordered to the east, west, north and south by the $290-\mathrm{km}$-long Guayape fault 


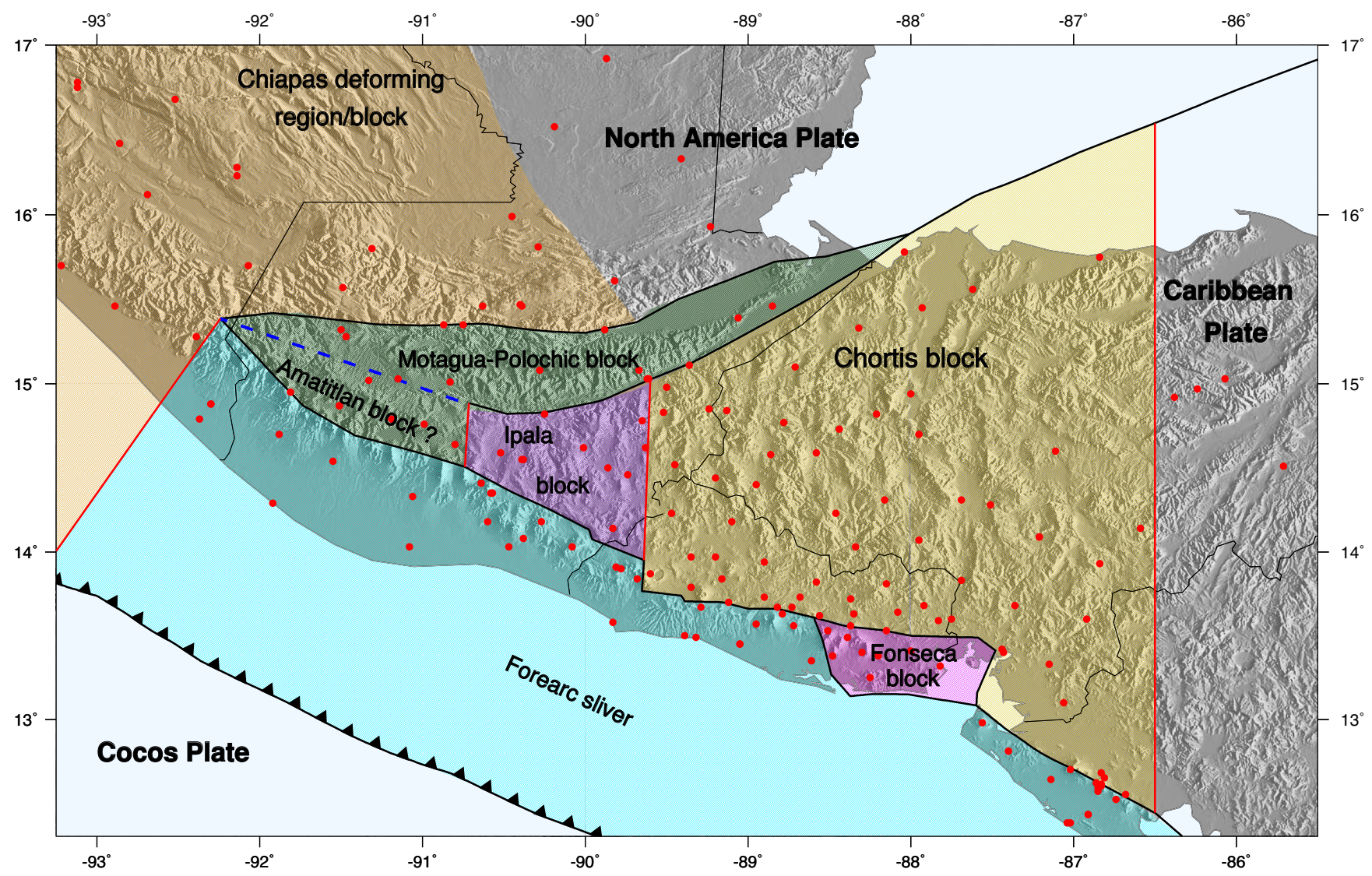

Figure 5. Plate and block configuration considered in this study, including possible Amatitlan and Chiapas blocks. The black lines indicate block and plate boundary faults where elastic locking was estimated. The red lines show free-slip boundaries. The dashed line shows a block boundary that was tested, but discarded for our models. The red circles identify GPS site locations from Fig. 2.

of central Honduras, the Guatemala City graben, the Motagua fault and the Central America volcanic arc, respectively (Figs 2and 6a). Hereafter, we refer to this triangular-shaped region as the Chortis extensional zone. In Section 4, we use our new velocity field to test for the existence of up to three blocks in the Chortis extensional zone, namely, the Chortis, Ipala and Amatitlan blocks (Fig. 5).

We digitized the plate and block boundaries from a variety of sources. The traces of the Swan Islands, Motagua and Polochic faults were variously digitized from Rosencrantz \& Mann (1991) and Authemayou et al. (2011). Faults in the volcanic arc were digitized from Funk et al. (2009), Alvarado et al. (2011), Canora et al. (2012) and high-resolution topographic maps. The subduction zone depth contours are from the Slab1.0 model (Hayes et al. 2012).

\subsection{Faults: subduction interface and strike-slip faults}

All the strike-slip faults in our model are represented by nodes that define a vertical fault between the surface and maximum permitted locking depths of $15 \mathrm{~km}$ for the Motagua, Polochic and Swan Islands faults and $10 \mathrm{~km}$ for the volcanic arc faults, where we assume a higher geothermal gradient. The faults consist of one or more connected sub-segments that terminate at along-strike discontinuities such as pull-apart basins or intersections with other faults. Only one locking depth and one locking ratio are estimated per fault subsegment, and the locking ratio is constrained to a value of 0 per cent (creeping) or 100 per cent (fully locked). We adopted this approach because our GPS data are too sparse in most areas to reliably estimate variable fault locking depths and fractional locking values due to trade-offs between these and other estimated parameters.

Based on depth contours from the Hayes et al. (2012) Slab1.0 compilation of subduction zone geometries, the Middle America subduction interface is approximated by 252 nodes that are spaced $40-80 \mathrm{~km}$ along-strike and $5 \mathrm{~km}$ in depth. Along-strike and downdip Laplacian smoothing of the individual node locking estimates is used in the inversion to avoid short-wavelength artefacts in the locking solution. We explored a range of possible smoothing factors in order to optimize the tradeoff between the data fit and complexity of the interseismic locking pattern for the Middle America subduction interface.

Our Supporting Information describes how our model results change if we vary the subduction zone geometry and locking depth that are used in our inversion. Although we did not examine whether our results changed significantly if we approximate the subduction interface with Slab2 subduction contours (Hayes et al. 2018), which became available after we completed this analysis, the Slab 2 interface differs relatively little from the Slab1.0 contours at depths shallower than $40 \mathrm{~km}$, but has a shallower dip at depths below $40 \mathrm{~km}$ for most of our study area. 



Figure 6. GPS site velocities in an east-to-west transect of the extending zone between the Motagua fault and volcanic arc. (a) GPS velocities relative to Caribbean plate for GPS sites with small elastic effects from the Motagua fault and volcanic-arc faults. (b) East velocity components for the sites from Panel A versus west-to-east distance along the transect. The filled and open red circles show continuous and campaign site rates, respectively. The grey circles are TDEFNODE preferred model estimates. (c) Enlargement of the western portion of (a) that compares our observed GPS site velocities (red) to the elastic-only (blue) component of each site velocity as estimated with our preferred TDEFNODE model. The black arrows in (a) and (c) and black circles in (b) are for three sites north of the Motagua Fault. All uncertainties are 1- $\sigma$. 


\subsection{Preferred inversion strategy}

After exploring numerous strategies for inverting our data with TDEFNODE, we adopted a preferred strategy that imposes relatively few a priori constraints on the solution and gives the best overall normalized least-squares fit to the observations (i.e. reduced chi-square or $\chi^{2}{ }_{v}$ ). Our preferred approach includes five a priori inputs to our TDEFNODE inversions, namely, predetermined angular velocities for the Caribbean and North America plates (Section 2 and Table 1), the MORVEL Cocos-Caribbean plate angular velocity (Table 1) and respective slip direction constraints of $\mathrm{N} 45^{\circ} \mathrm{W}-\mathrm{N} 60^{\circ} \mathrm{W}$ and $\mathrm{N} 40^{\circ} \mathrm{W}-\mathrm{N} 50^{\circ} \mathrm{W}$ at $12.6^{\circ} \mathrm{N}$ and $11.5^{\circ} \mathrm{N}$ along the Nicaraguan volcanic arc. The latter constraints encourage our elastic block model to predict dextral shear along the Nicaraguan volcanic arc, which is consistent with a recent structural interpretation (see fig. 22 in Funk et al. 2009).

The TDEFNODE parameter uncertainties are propagated from the data uncertainties and account for fitting tradeoffs between the model parameters. They do not account for additional uncertainties that can be introduced by factors such as incorrect locations, orientations and/or dips of the faults in the model, incorrect block geometries, imprecise a priori constraints on the inversion and possible systematic biases in the data. Throughout the analysis, we use results from five alternative inversions that are described in Section 2 of our Supporting Information in order to evaluate the robustness of our TDEFNODE model results and uncertainties.

\section{RESULTS}

We describe our results in several stages, reflecting the tectonic complexity of our study area. Section 4.1 describes the outcomes of tests to identify the block geometries that are the most consistent with our data and constraints. Section 4.2 describes the overall fit of our preferred model to the observations. Section 4.3describes results relevant to Cocos plate subduction, including interseismic locking of the subduction interface and our newly determined Cocos plate-forearc sliver angular velocity. Sections 4.4to 4.7describe in detail the observed and modelled GPS site velocities, fault slip rates and interseismic fault locking in the broadly deforming region north of the Polochic fault (Section 4.4), in the Chortis extensional zone (Section 4.5) and across the shear-dominated Motagua-Polochic fault zone (Section 4.6) and Central America forearc sliver (Section 4.7).

\subsection{Optimizing the block geometry}

Defining the appropriate block geometry for the Chortis extensional zone is critical for estimating slip rates along the Motagua fault and volcanic arc faults, which border the extensional zone. A simple examination of the velocities for the subset of the GPS sites that are located in the interior of the extensional zone, where the elastic effects from its bounding faults are small, is useful for defining the appropriate block geometry (Fig. 6). At the eastern end of the extending zone, we observe that the only GPS site east of the Guayape fault and the three sites immediately west of the fault move insignificantly relative to the Caribbean plate (Fig. 6a). Undeformed Caribbean plate thus extends west of the apparently inactive Guayape fault of central Honduras. Beginning $\approx 50 \mathrm{~km}$ west of the Guayape fault, the GPS sites all move $1-2 \mathrm{~mm} \mathrm{yr}^{-1}$ to the W-WNW (Fig. 6ab), indicating that a transition to deforming lithosphere occurs near $86.5^{\circ} \mathrm{W}$. We thus approximate the boundary between the
Caribbean plate and Chortis block with a north-south-trending, freeslip boundary at $86.5^{\circ} \mathrm{W}$ (Fig. 5).

From $86.5^{\circ} \mathrm{W}$ to $89^{\circ} \mathrm{W}$, the GPS site velocities rotate gradually $\approx 45^{\circ}$ anticlockwise and slowly increase in magnitude (Fig. 6a). Their west velocity component, which records E-W extension across the region's $\mathrm{N}-\mathrm{S}$ trending grabens, changes by less than $1 \mathrm{~mm} \mathrm{yr}^{-1}$ (Fig. 6b). Approximately $30-40 \mathrm{~km}$ east of the Ipala graben, the GPS site directions rotate anticlockwise by several tens of degrees (Fig. 6a) and the west component of the site motions increases to $2-3 \mathrm{~mm} \mathrm{yr}^{-1}$ (Fig. 6b). Based on these distinct changes, we hypothesize the existence of a distinct Ipala block and assign its boundary with the Chortis block to coincide with the eastern edge of the Ipala graben (Fig. 5).

Between the Ipala and Guatemala City grabens, the west component of the site velocities increases westward towards the Guatemala City graben (Fig. 6b), where a major velocity transition occurs (Fig. 6bc). We thus assign the Guatemala City graben as the western boundary of the hypothesized Ipala block (Fig. 5).

We tested for the existence of the Ipala block by inverting the GPS velocities and other data described in Section 2with block geometries that include or exclude the hypothesized block. For a block geometry that simplistically assumes that the entire Chortis extensional zone consists of a single, deforming Chortis block, an inversion of the data described in Section 2using the modelling approach outlined in Section 3gives a least-squares misfit $\chi^{2}=$ 1722.2. An inversion of the same data for a geometry that subdivides the same region into internally deforming Chortis and Ipala blocks (Fig. 5) improves the fit to $\chi^{2}=1290.7$. Six additional parameters are estimated for the latter model, consisting of the additional angular velocity and strain-rate tensor for the Ipala block. An $F$-ratio comparison of the two fits gives $F=25.3$. The probability is only $1 \times 10^{-25}$ that the improvement in fit is a random outcome of fitting the data with the six additional parameters. Our preferred block configuration thus includes an internally deforming Ipala block. $F$-ratio comparisons of the fits for other inversions that variously include or exclude strain-rate tensors for the Chortis and Ipala blocks indicate that strain-rate tensors for both blocks are justified at high confidence levels.

We similarly tested for the existence of a distinct Amatitlan block west of the Guatemala City graben (Fig. 5). Since there are no obvious faults that define its boundaries, we tested a variety of possible geometries. None however support the existence of an independent block west of the Guatemala City graben. A block geometry in which the lithosphere immediately west of the Guatemala City graben moves with the elongate Motagua-Polochic block (Fig. 5) gives the best fit to our kinematic data.

Based on compelling seismic and structural evidence for deformation in a broad region north of the Polochic fault (e.g. GuzmanSpeziale 2010; Witt et al. 2012), we also tested whether the data warrant including a deforming Chiapas block (Fig. 5). We used the region of elevated topography and seismicity north from the Polochic fault to approximate the Chiapas block boundaries (Figs 1and 5). Inversions with and without an angular velocity and horizontal strainrate tensor for a distinct Chiapas block give $\chi^{2}=1257.0$ and $\chi^{2}=$ 1290.7, respectively. Comparing the fits with the F-ratio test gives $F=2.0$, which has a probability value of only 93.6 per cent for the additional six estimated parameters. Our preferred block geometry thus does not include a Chiapas block.

Several factors may contribute to our failure to resolve a Chiapas block. Viscoelastic effects that are ignored by our simple elastic half-space model (Li et al. 2015) may contribute to our inability to fit the data, as may possible biases in some of our GPS site 
velocities due to uncorrected viscoelastic effects from large historic earthquakes offshore from Chiapas. Uncertainties in the assumed geometry and maximum locking depth for the subduction interface may contribute. Finally, the GPS station coverage in southern Mexico (Fig. 2) may be too sparse to separate inland-directed elastic shortening caused by subduction interface locking from the effects of long-term, distributed deformation in and near Chiapas, particularly if the primary direction of upper-plate deformation is parallel or sub-parallel to the interseismic elastic shortening direction (Andreani \& Gloaguen 2016).

\subsection{Preferred model summary}

Our preferred model is based on an inversion of 402 north and east GPS site velocity components, 11 fault azimuths, 188 earthquake slip directions (Section 2) and five a priori constraints (Section 3.4). Angular velocities are estimated for the forearc sliver and the Chortis, Ipala, Fonseca and Motagua-Polochic blocks, constituting 15 adjustable parameters. Horizontal strain-rate tensors are estimated for the Chortis, Fonseca and Ipala blocks, constituting nine additional parameters. Fractional fault locking ratios are estimated at 125 Middle America trench nodes. Finally, fault locking ratios of 0 or 1 and fault locking depths are estimated for all the strike-slip fault sub-segments.

The preferred model WRMS misfits are $1.00 \mathrm{~mm} \mathrm{yr}^{-1}$ for the GPS site velocity components, $4.2^{\circ}$ for the fault azimuths and $6.7^{\circ}$ for the earthquake slip directions. Per block or plate, the WRMS values vary from $0.5 \mathrm{~mm} \mathrm{yr}^{-1}$ for sites on the Caribbean plate to $1.4 \mathrm{~mm} \mathrm{yr}^{-1}$ for the 47 forearc sliver sites. These compare favourably with a $1.0 \mathrm{~mm} \mathrm{yr}^{-1}$ WRMS model misfit and 0.6 $1.4 \mathrm{~mm} \mathrm{yr}^{-1}$ block-specific WRMS misfits from similar block modelling of 1523 GPS site velocities from the southwestern United States (McCaffrey 2005).

Reduced chi-square $\left(\chi^{2}{ }_{v}\right)$ for the model is 2.84 implying that the average data misfit is 1.7 times larger than the estimated uncertainty. Factors that may contribute to the higher-than-expected misfits include the usual random data errors, errors due to imperfect coseismic and time-dependent post-seismic corrections from the first stage of this analysis (Ellis et al. 2018) and model-related misfits such as errors in our assigned block geometries, distributed deformation within blocks that are assumed to be rigid, imprecise a priori constraints on the inversion and viscoelastic deformation not accounted for by our elastic model (e.g. Li et al. 2015). Sensitivity and robustness tests that are described below suggest that the TDEFNODE model uncertainties are realistic despite the higherthan-expected misfits.

\subsection{Cocos plate subduction: plate motion and subduction interface locking}

Our newly estimated angular velocity for the Cocos plate relative to the forearc sliver (Table 1) predicts convergence directions that vary from $\mathrm{N} 27.5^{\circ} \mathrm{E}$ to $\mathrm{N} 30^{\circ} \mathrm{E}$ along the trench (Fig. 4), close to the earthquake slip directions and only $3^{\circ}$ different from the N31$32^{\circ} \mathrm{E}$ average convergence direction that is estimated by GuzmanSpeziale \& Zuniga (2016) from thrust earthquakes in this region. The new angular velocity predicts that the Cocos plate subducts more rapidly beneath the forearc sliver than does the MORVEL Cocos-Caribbean angular velocity (compare red and blue arrows in Fig. 7a), reaching a maximum difference of $10.6 \mathrm{~mm} \mathrm{yr}^{-1}$ offshore from the Mexico-Guatemala border.
The uncertainties in the convergence rates and directions determined from Cocos-forearc sliver angular velocity covariances (Table 1) average $\pm 4 \mathrm{~mm} \mathrm{yr}^{-1}$ and $\pm 3.5^{\circ}$ (95 per cent) along the plate boundary. Convergence directions and rates that are predicted by Cocos-forearc sliver angular velocities that we derived from five alternative block models that relax or apply different model constraints and/or modelling assumptions (described in Section S2 of the Supporting Information) differ from our preferred estimate by no more than $\pm 1.1^{\circ}$ and +5 and $-2 \mathrm{~mm} \mathrm{yr}^{-1}$. Given that the 95 per cent uncertainties in the Cocos-forearc sliver convergence velocities predicted by our preferred model include the velocities that are predicted by most of the alternative models, we consider the preferred model uncertainties to be realistic.

Our preferred model indicates that locking of the Middle America subduction interface changes from moderate-to-high (average of 65 per cent locking) offshore from Chiapas (Fig. 7a) to low (average of 16 per cent) offshore from southern Guatemala, El Salvador and northern Nicaragua, with the transition occurring offshore from the Mexico-Guatemala border. The locking estimates agree well with the approximate limits suggested by simple 1-D forward modelling for these regions, as shown in Fig. S4 of the Supporting Information.

We used two methods to evaluate the robustness of the preferred locking solution, namely, checkerboard tests and sensitivity tests based on plausible changes to our modelling assumptions. Inversions of synthetic GPS velocities created with starting solutions in which locking on the subduction interface changes systematically with depth but remains constant along strike could not recover the depth-varying starting solution. In contrast, inversions of synthetic GPS velocities created with starting solutions that include one along-strike change in the degree of subduction locking, but no variations with depth accurately recover the starting solution for a wide range of assumed transitional locations in the locking. We conclude that the major along-strike change in locking offshore from the Mexico-Guatemala in our preferred model (Fig. 7a) is well resolved, but that locking depths are poorly resolved everywhere offshore from our study area.

Figs S11(b)-(f) of the Supporting Information display five alternative solutions for the subduction interface locking from inversions in which we varied some of the assumptions and constraints in our preferred TDEFNODE model (as described in Section 2of the Supporting Information). The average locking values for the subduction interface below the forearc sliver vary from 3 to 27 per cent for the five models. The same models give average locking estimates of 40 to 72 per cent for the Cocos-North America subduction interface offshore from Chiapas. Assuming that these approximate to 95 per cent lower and upper limits for the locking, then the subduction interface locking averages $16 \pm 12$ per cent beneath the forearc sliver and $65_{-20}^{+7}$ per cent offshore from Chiapas.

Based on the above, we conclude with high confidence that a transition from low interseismic locking beneath the forearc sliver to moderate locking beneath the North America plate occurs offshore from the Mexico-Guatemala international border (Fig. 7a). Our $16 \pm 12$ per cent estimate for locking below the forearc sliver agrees with a seismically derived 10 per cent estimate for the same region (Guzman-Speziale \& Gomez-Gonzalez 2006) and is intermediate between 0-3 per cent and 25-34 per cent locking averages previously estimated from geodetic data (Correa-Mora et al. 2009; Franco et al. 2012). Our $65_{-20}^{+7}$ per cent locking estimate offshore from Chiapas agrees well with 80 per cent and 60-80 per cent seismic and geodetic locking estimates from Guzman-Speziale \& Gomez-Gonzalez (2006) and Franco et al. (2012). 


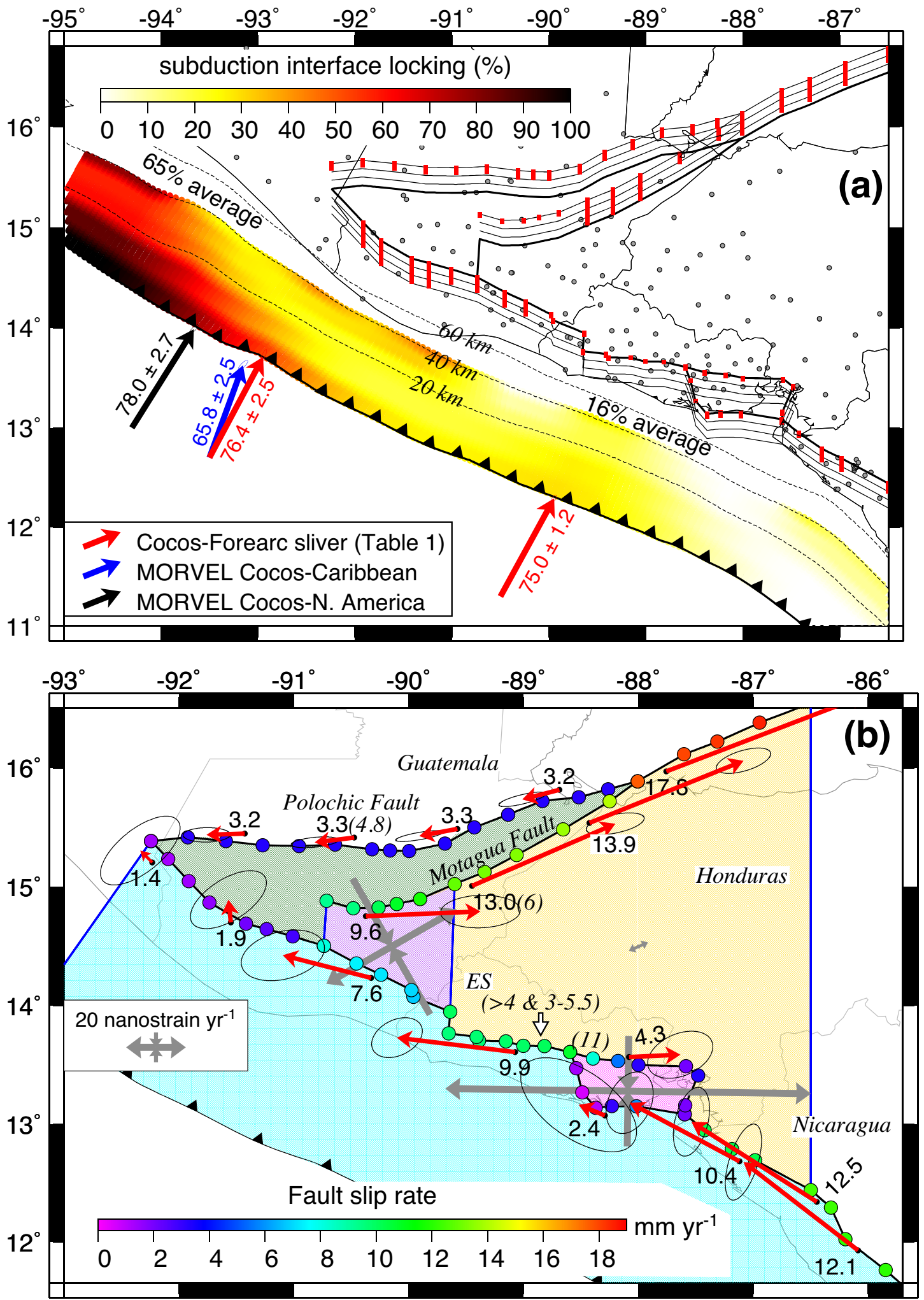

Figure 7. (a) Preferred-model fault locking solutions and Cocos plate convergence velocities with 1- $\sigma$ uncertainties and (b) fault slip rate and block strain-rate estimates. Fault locking is expressed as a percentage of the full fault slip rate. Fence diagrams in (a) show perspective depth views of the strike-slip faults downward in 5-km depth intervals. The red circles show the fully locked fault segments and extend downwards to the maximum estimated fault locking depth. The shallowest level of each strike-slip fault faces the upper edge of the diagram. The black circles in (a) show GPS site locations. The slip rates in (b) estimated at the strike-slip fault nodes are colour-coded according to the scale on the map. The red arrows and their adjacent numbers show velocities estimated for the plate or block on which each arrow originates relative to the plate or block across the adjacent strike-slip fault. Slip rates in (a) and (b) have units of mm $\mathrm{yr}^{-1}$. If available, published geologic fault slip rates are given parenthetically. The grey double-headed arrows show the estimated strain-rate axes from Table 2. The outward-pointing arrows indicate extensional strain rates. Abbreviation: ES; El Salvador. 



Figure 8. Interseismic elastic (a) and long-term (b) velocity components of motion estimated with the preferred TDEFNODE model at each GPS site. The interseismic velocity component shows the summed elastic deformation at each GPS site for the fully or partially locked fault nodes in Fig. 7(a). The modelled (black) long-term site velocity component is due to the estimated rotation and internal distributed deformation of each site's plate or block. The velocities in (b) are relative to a stationary Caribbean plate. 
Table 2. Best-fitting horizontal strain-rate tensors: principal components.

\begin{tabular}{|c|c|c|c|c|c|}
\hline $\begin{array}{l}\text { Block } \\
\text { name }\end{array}$ & \multicolumn{2}{|c|}{ Block centroid } & $\dot{\epsilon}_{1}$ & $\dot{\epsilon}_{2}$ & $\begin{array}{c}\text { Azimuth } \\
\dot{\epsilon}_{1}\end{array}$ \\
\hline Chortis & 14.500 & -88.000 & $7.0 \pm 3.7$ & $1.7 \pm 3.7$ & $66.3 \pm 25.0$ \\
\hline Fonseca & 13.279 & -88.090 & $122.5 \pm 60.2$ & $-37.0 \pm 40.9$ & $-89.2 \pm 19.7$ \\
\hline
\end{tabular}

$\overline{\dot{\epsilon}_{1} \text { and } \dot{\epsilon}_{2} \text { are the principal axes of the horizontal strain-rate tensor, corresponding to the largest and smallest extensional strain rate axes. The last column gives }}$ the direction of $\dot{\epsilon}_{1}$ in degrees clockwise from north.

The along-strike change in the subduction interface locking indicated by our model is accompanied by an along-strike change in the modelled rates of interseismic elastic shortening in our study area (Fig. 8a). In Chiapas, our modelled elastic shortening rates decrease from $\approx 10 \mathrm{~mm} \mathrm{yr}^{-1}$ along the coast to only $2 \mathrm{~mm} \mathrm{yr}^{-1} \approx 200 \mathrm{~km}$ inland (Fig. 8a). In El Salvador and Honduras, the modelled elastic shortening rates are only $1-3 \mathrm{~mm} \mathrm{yr}^{-1}$ along the coast and diminish to under $1 \mathrm{~mm} \mathrm{yr}^{-1}$ farther inland (also see Figs S4b and $\mathrm{c}$ in the Supporting Information). The slow, NE-directed elastic shortening predicted in the Chortis extensional zone (red arrows in Fig. 8a) is orthogonal to the observed GPS site motions, which instead point to the WNW-NW (red arrows in Figs 3 and $8 \mathrm{~b}$ ). The difference between the measured station motions and their modelled, interseismic elastic component of motion is accounted for by a modelled long-term component of the site motions that is dominantly directed to the WNW (the black arrows in Fig. 8b).

\subsection{Chiapas and areas north of the Polochic fault}

North of the western Polochic fault in Guatemala and southern Mexico (Fig. 9), numerous reverse and strike-slip faults accommodate distributed deformation within a wide area referred to as the Chiapas Tectonic Province (Guzman-Speziale et al. 1989; GuzmanSpeziale \& Meneses-Rocha 2000; Guzman-Speziale 2010; Authemayou et al. 2011). Evidence that the region is actively deforming includes large historic earthquakes in 1591 (M7.2-7.6) and 1902 (M7.6-7.8) (Guzman-Speziale \& Meneses-Rocha 2000; Witt et al. 2012) and numerous smaller, shallow-crustal earthquakes with strike-slip and reverse-faulting focal mechanisms (Fig. 9).

Relative to the North America plate, sites in the Chiapas Tectonic Province and other areas north of the Polochic fault move inland at an average direction of $\mathrm{N} 37^{\circ} \mathrm{E}$ at rates of $10 \mathrm{~mm} \mathrm{yr}^{-1}$ or slower (red arrows in Fig. 9and Figs S2 and S4 in the Supporting Information). For comparison, the Cocos-North America angular velocity that we use to constrain our inversion (Table 1) predicts a $\mathrm{N} 31^{\circ} \mathrm{E}$ plate convergence direction offshore from Chiapas. The directions and inland-decreasing rates for the observed GPS velocities are both consistent with elastic shortening of a plate inland from a locked subduction interface.

Our preferred model overestimates the observed motions at the coastal sites by $2-4 \mathrm{~mm} \mathrm{yr}^{-1}$, but underestimates by $1-3 \mathrm{~mm} \mathrm{yr}^{-1}$ the velocities of sites farther inland (Fig. 10and Supporting Information Fig. S10). The misfits are the largest in our study area and constitute the only coherent pattern in the residual velocities. We consider it unlikely that the misfits are evidence for a bias in our a priori estimate of the North America-ITRF08 angular velocity because the velocities of four of the five GPS sites in the Yucatan peninsula, where any elastic effects from the trench locking are small, are fit by our North America-ITRF08 angular velocity to within $0.5-0.7 \mathrm{~mm} \mathrm{yr}^{-1}$ (Fig. S10 in the Supporting Information).
We also consider it unlikely that the misfits are artefacts of an incorrect assumed locking depth or geometry for the subduction interface since models that use a different subduction geometry and/or locking depth do not significantly improve the fit (Sections S2.2 and S2.3 of the Supporting Information).

A more promising approach to resolving the misfits may be to incorporate viscoelastic effects into future models. From 2-D finite element modelling of a generic subduction zone, Li et al. (2015) show that locking of the subduction interface not only gives rise to well-understood elastic shortening of the crust, but also causes a build-up of crustal stresses that are relieved via viscous surface deformation that contributes significantly to late-stage interseismic deformation. Their modelling not only predicts significantly more late-stage interseismic deformation across a wider zone onshore than do purely elastic models, but indicates that purely elastic models tend to overestimate elastic shortening rates at near-coastal sites and underestimate shortening rates at sites far inland. This describes the pattern of misfit in Chiapas (blue arrows in Fig. 9), suggesting a fruitful avenue for future work in this area.

\subsection{Chortis and Ipala block motions and distributed extension south of the Motagua fault}

Our new velocities include 76 GPS sites on the Chortis and Ipala blocks, which occupy the Chortis extensional zone (e.g. Fig. 5). The residual velocities at the 66 Chortis block and 10 Ipala block GPS sites velocities (blue arrows in Fig. 10a and red arrows in Fig. S10 of the Supporting Information) appear to be random and have respective WRMS misfits of 0.91 and $0.46 \mathrm{~mm} \mathrm{yr}^{-1}$, better than the WRMS misfit average of $1.0 \mathrm{~mm} \mathrm{yr}^{-1}$ for the whole velocity field.

The modelled velocities for most sites on the Chortis and Ipala blocks are a combination of interseismic elastic movement due to the locked faults in our model (Fig. 8a) and the long-term motion (Fig. 8b) due to block rotations (Table 1) and internal block deformation (Table 2). The rates and directions of deformation internal to each block, which are estimated using the block strain-rate tensor, are determined relative to the block centroid, such that E-W elongation across a block gives rise to west-directed movement at all locations west of the block centroid, but east-directed movement at all locations east.

Based on the Chortis and Ipala block angular velocities relative to the Caribbean plate (Table 1) and strain-rate tensors (Table 2), the crustal velocities that are predicted by our preferred TDEFNODE model along a 450-km-long transect of the Chortis extensional zone between undeformed Caribbean plate lithosphere in central Honduras and a location $\approx 50 \mathrm{~km}$ west of the Guatemala City graben are as follows: At the eastern boundary of the Chortis block in central Honduras, our model estimates a crustal velocity of $1.9 \mathrm{~mm} \mathrm{yr}^{-1}$ towards $\mathrm{N} 53^{\circ} \mathrm{W}$, increasing to $2.4 \pm 0.7 \mathrm{~mm} \mathrm{yr}^{-1}$ towards $\mathrm{N} 70^{\circ} \mathrm{W}$ $\pm 15^{\circ}$ at the block centroid and $3.2 \mathrm{~mm} \mathrm{yr}^{-1}$ towards $\mathrm{N} 77^{\circ} \mathrm{W}$ at the 


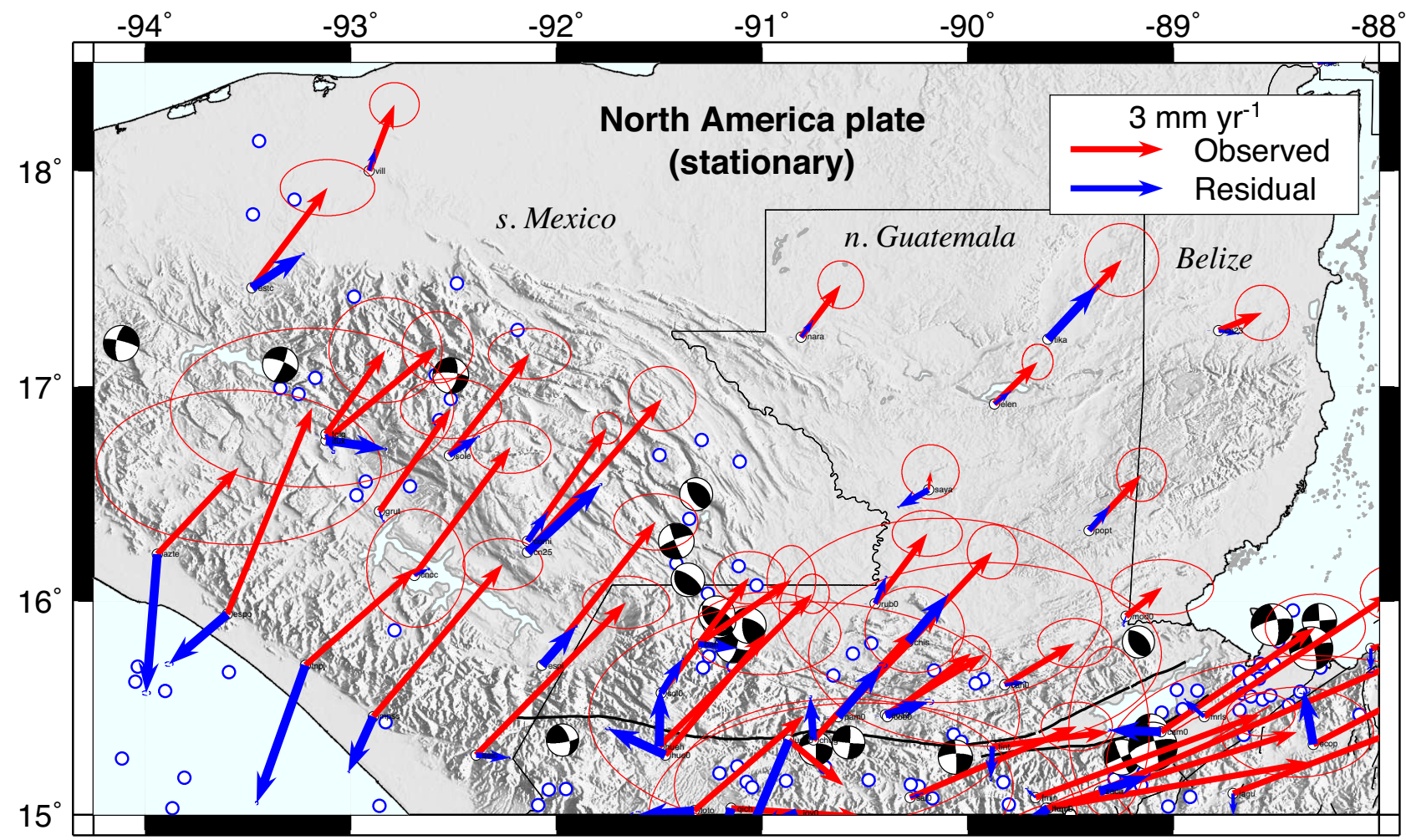

Figure 9. Observed GPS site velocities (red) with 1- $\sigma$ uncertainties and residual velocities (blue) in the northern portion of our study area (region defined in Fig. 2). Residuals are defined as the observed reduced by the velocities estimated with our preferred TDEFNODE model. The site velocities are relative to a stationary North America plate. Earthquake focal mechanisms are from sources listed in the Fig. 1caption. Earthquake epicentres from the International Seismological Centre catalogue for 1964 to 2008 are shown by the blue circles.

western block boundary adjacent to the Ipala graben. The strain-rate tensor predicts an integrated elongation rate across the $\approx 300-\mathrm{km}-$ wide Chortis block of $1.8 \pm 0.9 \mathrm{~mm} \mathrm{yr}^{-1}$.

Our model predicts divergence of $1.8 \mathrm{~mm} \mathrm{yr}^{-1}$ directed $\mathrm{N} 82^{\circ} \mathrm{E}-$ $\mathrm{S} 82^{\circ} \mathrm{W}$ for the Ipala graben, nearly orthogonal to the graben. This first-ever estimate of the deformation rate and direction for the Ipala graben accounts for the relative rotation between the Ipala and Chortis blocks across the graben and the contributions from the strain-rate tensors for the two blocks.

Our TDEFNODE model predicts motion of $6.1 \pm 1.7 \mathrm{~mm} \mathrm{yr}^{-1}$ towards $\mathrm{N} 71^{\circ} \mathrm{W} \pm 11^{\circ}$ at the centre of the Ipala block, increasing to $7.1 \pm 1.7 \mathrm{~mm} \mathrm{yr}^{-1}$ towards $\mathrm{S} 61^{\circ} \mathrm{W} \pm 11^{\circ}$ at the block's western edge near the Guatemala City graben (Figs $6 \mathrm{~b}$ and $8 \mathrm{~b}$ ). The Ipala block strain-rate tensor predicts an integrated elongation rate of $5 \pm 2 \mathrm{~mm} \mathrm{yr}^{-1}$ oriented $\mathrm{N} 60^{\circ} \mathrm{E}-\mathrm{S} 60^{\circ} \mathrm{W}$ across the $\approx 100$ - $\mathrm{km}$-wide block.

Our model predicts rapid extension rates at the western limit of the Chortis extensional zone, coinciding with the Guatemala City graben and a series of NE-trending normal faults to the west of the graben. Between the eastern edge of the Guatemala City graben and the continuous GPS site TECP $50 \mathrm{~km}$ west of the graben (located in Fig. 8 b), our model predicts $8.5 \pm 2.2 \mathrm{~mm} \mathrm{yr}^{-1}$ of nearly E-W divergence, of which $\approx 5 \mathrm{~mm} \mathrm{yr}^{-1}$ appears to be accommodated by the Guatemala City graben (Figs $6 \mathrm{~b}$ and c) and the remaining $3 \mathrm{~mm} \mathrm{yr}^{-1}$ by the normal faults west of the graben. Franco et al. (2012) previously estimated that the graben accommodates $\approx 5 \mathrm{~mm} \mathrm{yr}^{-1}$ of divergence, consistent with our estimate. The velocities at our new GPS sites west of the graben show for the first time that significant additional extension also occurs west of the graben, but is limited to areas within $\approx 50 \mathrm{~km}$ of the graben.
4.6 Motagua and Polochic faults: fits, locking depths, slip rates and slip partitioning

The Motagua-Polochic fault zone, which accommodates most of the motion between the Caribbean and North America plates in our study area, is the principal physiographic and tectonic feature in our study area. The 1816 July $22 M_{\mathrm{w}} \approx 7.5$ earthquake on the Polochic fault (White 1985) and 1976 February $04 M_{\mathrm{w}}=7.5$ Motagua fault earthquake (Plafker 1976) established that both faults are active and seismically hazardous, making them an early target of geodetic studies in this region (Lyon-Caen et al. 2006). Below, we briefly describe the subset of our data and results that are relevant to the fault zone, with emphasis on the slip rates for both faults and their partitioning of the plate motion.

\subsubsection{Observed site velocities and model fits}

Fig. 11 shows the velocities of all GPS sites within $\approx 150 \mathrm{~km}$ of the fault zone, including many new sites south of Motagua fault and north of the eastern and central Polochic fault where few or no sites were available for previous studies (Lyon-Caen et al. 2006; Franco et al. 2012). The velocities of GPS sites within transects of the fault zone in eastern and central Guatemala change by $17-18 \mathrm{~mm} \mathrm{yr}^{-1}$ between the ends of the transects (Supporting Information Fig. S5), but by only $10-12 \mathrm{~mm} \mathrm{yr}^{-1}$ for a transect in central Guatemala (Supporting Information Fig. S6a) and by less than $2 \mathrm{~mm} \mathrm{yr}^{-1}$ for the transect west of the Guatemala City graben (Supporting Information Fig. S6b). The observations thus clearly show that the fault zone slip rate diminishes to the west, consistent with the significant difference in slip rates that was first reported by Lyon-Caen et al. (2006). 

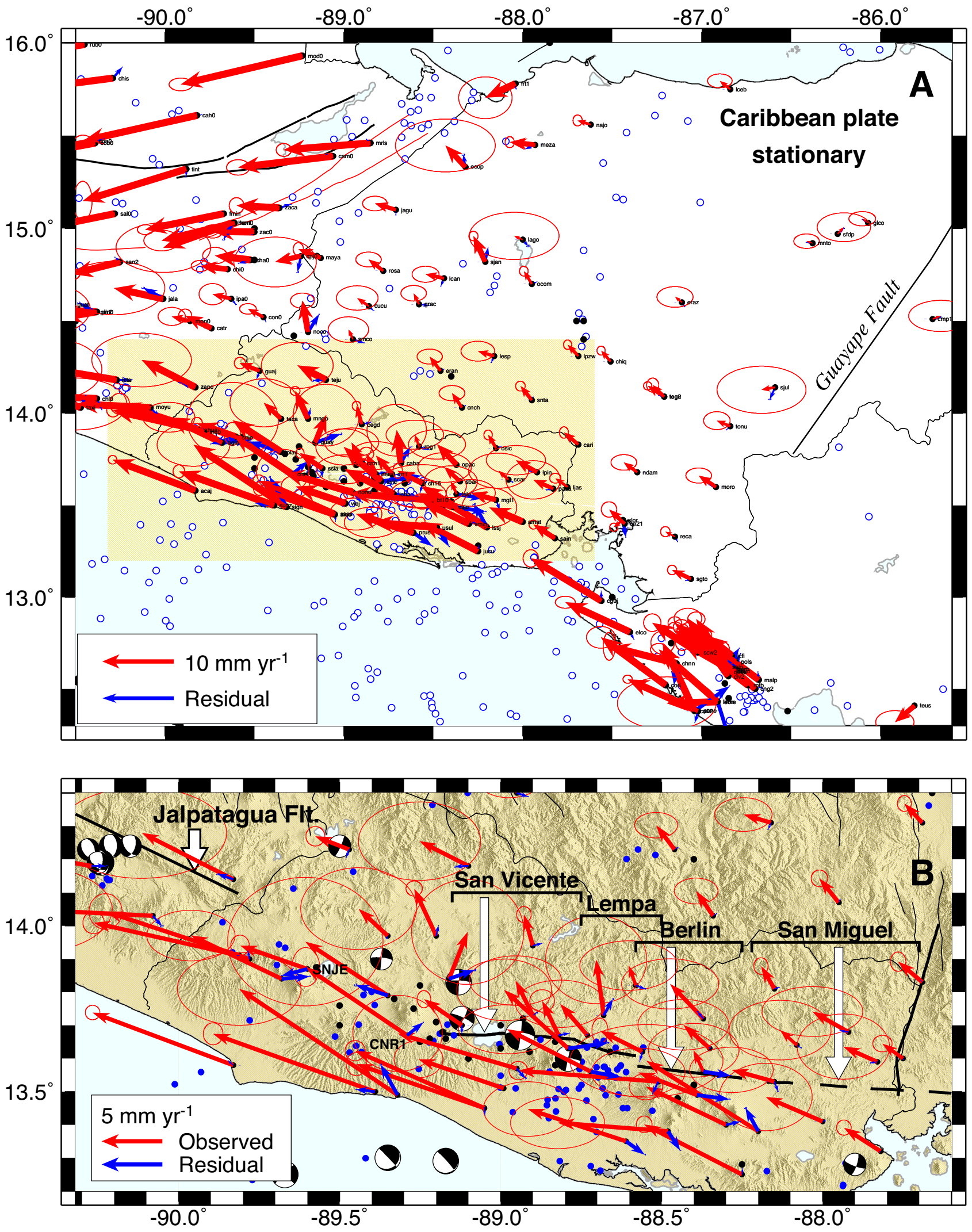

Figure 10. Observed GPS site velocities (red) and 1- $\sigma$ uncertainties relative to a stationary Caribbean plate versus residual velocities (blue) from our preferred TDEFNODE model. The gold-shaded region in (a) is enlarged in (b). The bold lines in (b) demarcate El Salvador Fault Zone strike-slip faults that accommodate movement of the forearc sliver. The along-strike limits of the San Vicente, Lempa, Berlin and San Miguel fault segments are defined and labelled. Earthquake focal mechanisms are from sources listed in the Fig. 1caption. Earthquake epicentres from the 1964-2008 International Seismological Centre catalogue (1964 to 2008) and the Guzman-Speziale et al. (2005) compilation for historic earthquakes since 1586 are shown by the blue and black circles, respectively. 


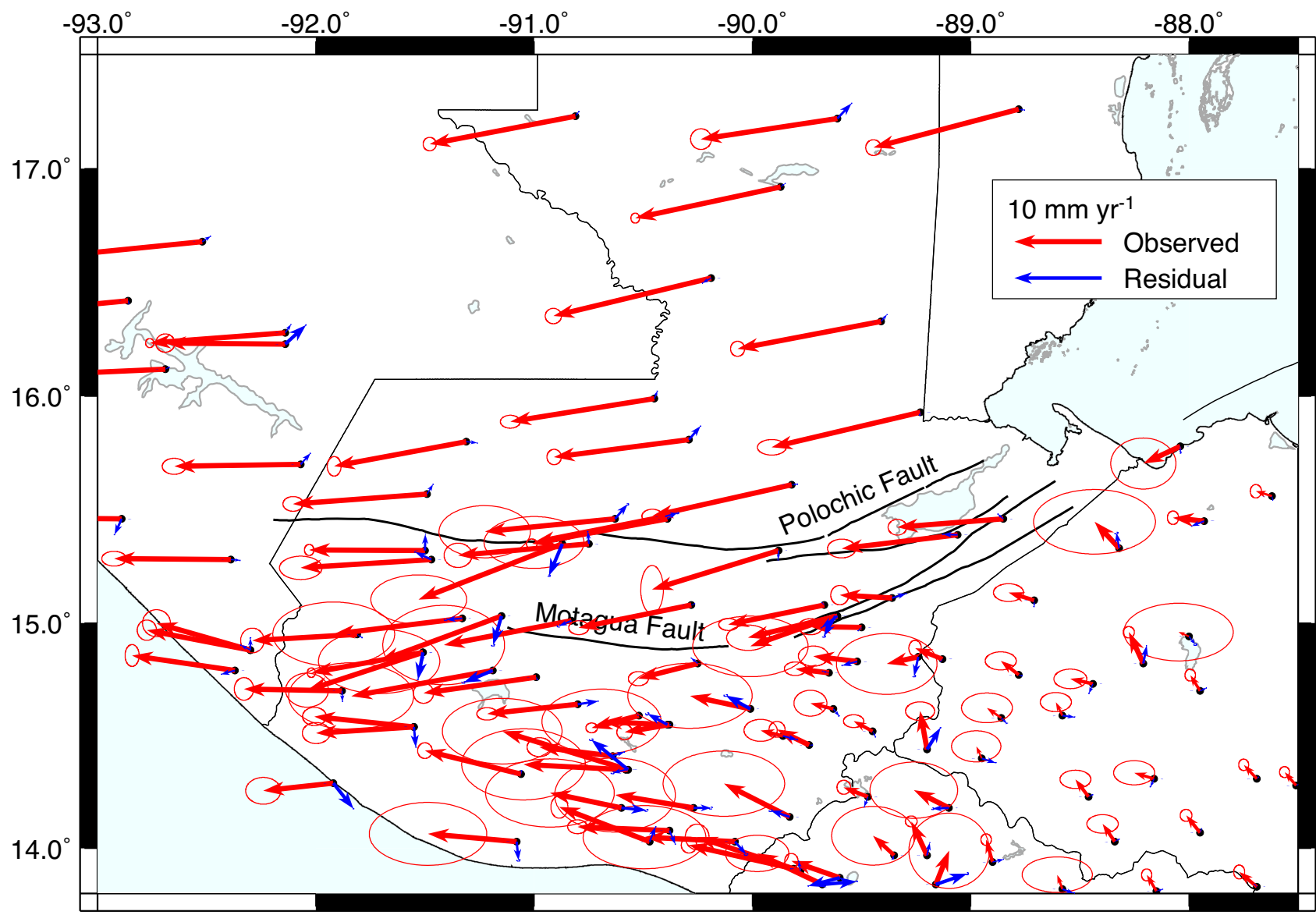

Figure 11. Observed GPS site velocities (red) with 1- $\sigma$ uncertainties and residual velocities (blue) in the central portion of our study area (region defined in Fig. 2). Residuals are defined as the observed reduced by the velocities estimated with our preferred TDEFNODE model. The site velocities are relative to a stationary Caribbean plate.

Our preferred model fits the velocities of GPS sites everywhere along the fault zone well, with typical misfits that are smaller than $1 \mathrm{~mm} \mathrm{yr}^{-1}$ and within the estimated $1-\sigma$ velocity uncertainties (the fits and misfits are variously shown in Fig. 11 and the Supporting Information Figs S5, S6 and S10). The good fits indicate that our adopted block geometries, model parametrization and model/data constraints are adequate to characterize the regional velocity field, including the aforementioned along-strike changes in the fault slip rates.

\subsubsection{Motagua fault slip rates and uncertainties}

Our new model predicts that slip rates on the Motagua fault decrease westwards from $14.2 \pm 1.6 \mathrm{~mm} \mathrm{yr}^{-1}$ at the fault's eastern intersection with the Swan Islands fault to $13.0 \pm 1.6 \mathrm{~mm} \mathrm{yr}^{-1}$ at its intersection with the Ipala graben to $9.2 \pm 2.2 \mathrm{~mm} \mathrm{yr}^{-1}$ at its intersection with the Guatemala City graben (Fig. 7b). The decrease in the estimated slip rate where the Motagua fault borders the Chortis block is a consequence of distributed deformation within the Chortis block (Section 4.5), which gradually transfers motion southwards off from the Motagua fault.

West of the Ipala graben, where the Motagua fault borders the Ipala block (Fig. 7b), the decrease in the fault slip rate from $12.4 \mathrm{~mm} \mathrm{yr}^{-1}$ at the fault's intersection with the Ipala graben to $9.2 \mathrm{~mm} \mathrm{yr}^{-1}$ at its intersection with the Guatemala City graben is similarly accommodated via a transfer of slip southwards from the fault onto structures within the extending Ipala block.

At the intersection of the Motagua fault with the Guatemala City graben, our model predicts that all $9.2 \pm 2.2 \mathrm{~mm} \mathrm{yr}^{-1}$ of slip remaining on the fault is transferred southwards into the Guatemala City graben. This is overly simplistic. Instead, the measured rates for GPS sites GUAT, CML0 and TECP, which span and extend $\approx 50 \mathrm{~km}$ west of the Guatemala City graben, increase gradually from east to west by $8 \mathrm{~mm} \mathrm{yr}^{-1}$ (Figs $6 \mathrm{~b}$ and c). The velocity gradient defined by these stations indicates that slip is transferred gradually southwards from the Motagua fault into the Guatemala City graben and onto other N-to-NE striking faults that intersect the Motagua fault west of and within $\approx 50 \mathrm{~km}$ of the Guatemala City graben. The Motagua fault, thus remains active west of the Guatemala City graben, but its slip rate diminishes rapidly from $9 \mathrm{~mm} \mathrm{yr}^{-1}$ at its intersection with the graben to only $0-2 \mathrm{~mm} \mathrm{yr}^{-1}$ within $50 \mathrm{~km}$ west of the graben (Fig. 6c). Given that the same N- to NE-trending faults west of the Guatemala City graben ruptured in the hours and days after the $1976 M_{\mathrm{s}}=7.5$ Motagua fault strike-slip earthquake (Langer $\&$ Bollinger 1979), the faults are clearly active and constitute an important seismic hazard to this heavily populated region.

The five alternative models described in our Supporting Information variously predict slip rates of 12.1 to $13.9 \mathrm{~mm} \mathrm{yr}^{-1}$ for the central Motagua fault. These agree with the $13.0 \mathrm{~mm} \mathrm{yr}^{-1}$ preferred estimate within its 95 per cent uncertainty of $\pm 1.6 \mathrm{~mm} \mathrm{yr}^{-1}$. We 


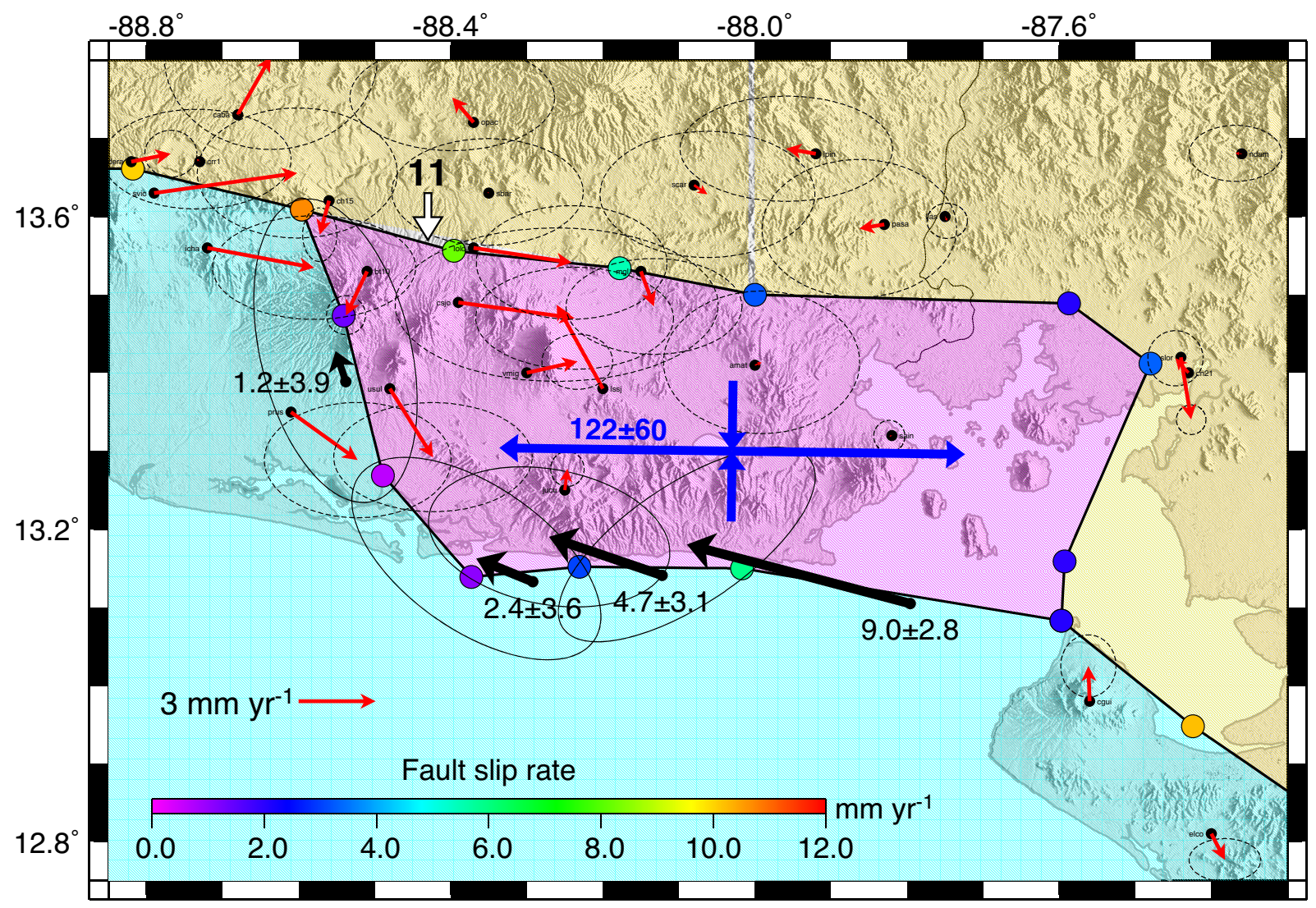

Figure 12. GPS site velocity misfits (red arrows), fault slip rate estimates (coloured circles), forearc sliver velocities relative to the Fonseca block (black arrows), principal strain-rate axes (blue) and strain-rate axis magnitudes in nanostrains (blue text). All estimates are for the preferred TDEFNODE model described in the text. The numeral '11' demarcates the section of the Berlin fault segment where Corti et al. (2005) use paleosurface and drainage offsets to estimate a minimum fault slip rate of $11 \mathrm{~mm} \mathrm{yr}^{-1}$.

conclude that our estimates of the Motagua fault slip rates and their uncertainties are robust.

Our newly estimated Motagua fault slip rates are 30-40 per cent slower than the 20 and $16 \mathrm{~mm} \mathrm{yr}^{-1}$ slip rates estimated by Franco et al. (2012) in eastern and central Guatemala. The newly determined slip rates, which are estimated from a model with Chortis and Ipala blocks on the southern edge of the Motagua fault and strain-rate tensors to accommodate distributed extension within both blocks, are slower than previous estimates, which assumed that undeforming Caribbean plate lies south of the Motagua fault.

\subsubsection{Polochic fault slip rates and uncertainties}

Along the Polochic fault, our preferred model predicts slip rates of 3.1 to $3.3 \pm 1.3 \mathrm{~mm} \mathrm{yr}^{-1}$ (Fig. $7 \mathrm{~b}$ ). Our slip rate estimate is more reliable for the eastern half of the Polochic fault than for its western half, where earthquakes and faulting north of the fault indicate that the slip on the Polochic fault is transferred gradually northwards to structures in the Chiapas Tectonic Province (Figs 1and 9).

The five alternative models that are described in Section 2of our Supporting Information predict Polochic fault slip rates as fast as $5.4 \mathrm{~mm} \mathrm{yr}^{-1}$ (Supporting Information Fig. S12a) and as slow as $1.7 \mathrm{~mm} \mathrm{yr}^{-1}$ (Supporting Information Fig. S13a). The $\pm 2.6 \mathrm{~mm} \mathrm{yr}^{-1} 95$ per cent uncertainty in our $3.2 \mathrm{~mm} \mathrm{yr}^{-1}$ preferred slip rate estimate encompasses these extremes, suggesting that the TDEFNODE uncertainty estimate is realistic. An alternative model with a deforming Chiapas block predicts that the estimated fault slip rate decreases from $4.1 \mathrm{~mm} \mathrm{yr}^{-1}$ in the east to only $1.7 \mathrm{~mm} \mathrm{yr}^{-1}$ along the western segment of the fault (Supporting Information Fig. S13a). In this model, more than $2 \mathrm{~mm} \mathrm{yr}^{-1}$ of Polochic fault slip is transferred northwards onto structures in southern Mexico.

\subsubsection{Plate motion partitioning: Motagua and Polochic faults}

The angular velocity for the Chortis block relative to North America (Table 1) predicts net relative motion of $17.8 \pm 0.8 \mathrm{~mm} \mathrm{yr}^{-1}$ across the Motagua-Polochic fault zone of eastern Guatemala (Fig. 7b). Of this, the Motagua and Polochic faults, respectively, accommodate $14.2 \pm 1.6$ and $3.3 \pm 1.3 \mathrm{~mm} \mathrm{yr}^{-1}$ of the plate motion. Our model thus predicts that $80 \pm 12$ per cent of the plate motion occurs along the Motagua fault, constituting the first rigorous estimate of how the plate motion is partitioned between the two faults. This agrees with the observation that the velocity gradient across the two faults is centred on the Motagua fault (Lyon-Caen et al. 2006 and the Supporting Information Fig. S5).

The Chortis-North America plate angular velocities we determined from five alternative inversions (Section 2 in the Supporting Information) predict relative motions along the Motagua-Polochic fault zone that differ from our preferred estimate by no more than $\pm 1 \mathrm{~mm} \mathrm{yr}^{-1}$ and $\pm 1.6^{\circ}$. That Chortis-North America plate motion is well determined is unsurprising given the numerous GPS site velocities that are used to estimate their angular velocities. The alternative models variously predict that the Motagua fault accommodates $70-80$ per cent of the plate motion. We conclude that our 


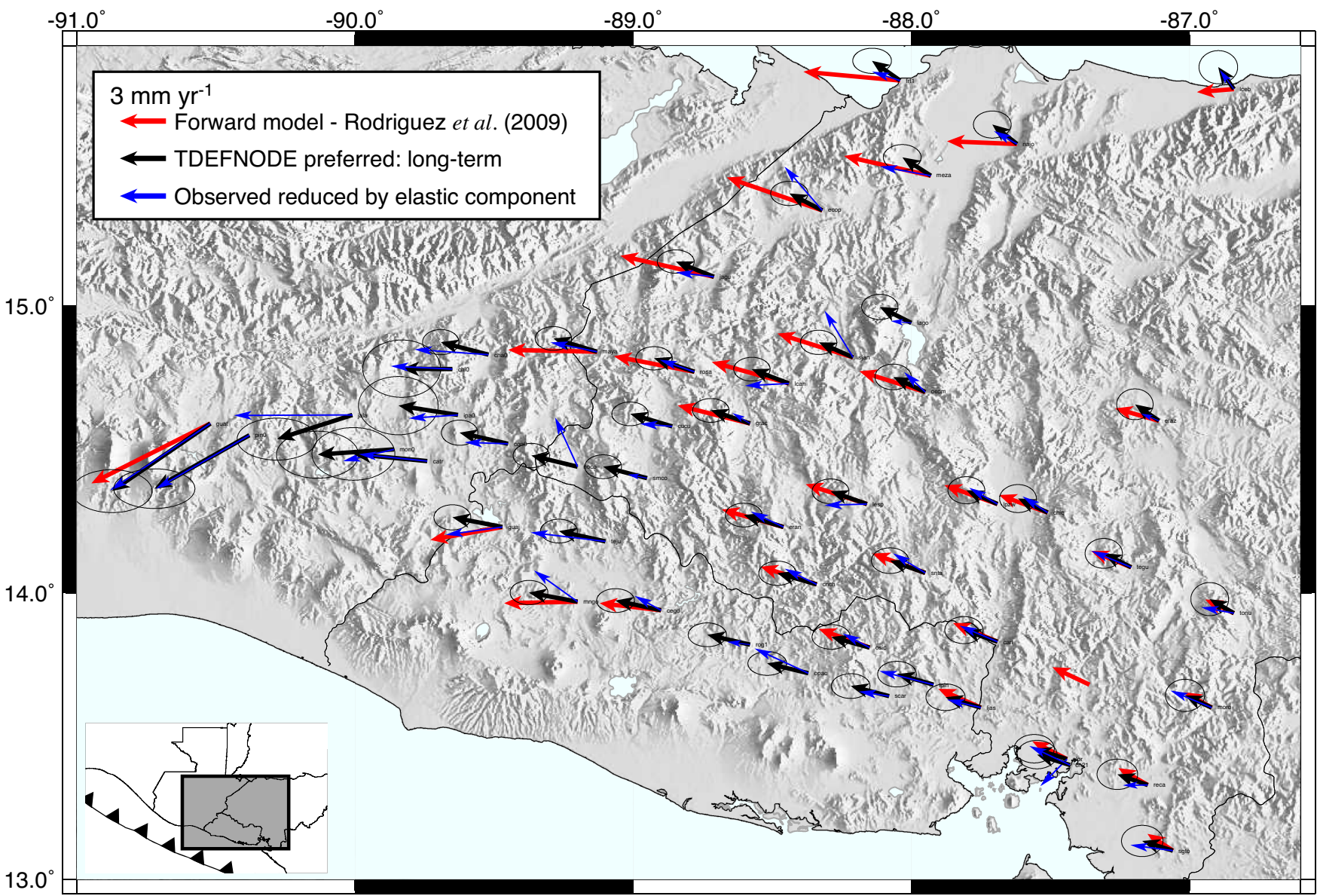

Figure 13. Velocities at GPS sites in the Chortis extensional zone relative to the Caribbean plate as predicted by the Rodriguez et al. (2009) CA103P thin-plate finite element model (red arrows), our preferred TDEFNODE inversion (black arrows), and our observed GPS velocities corrected by the elastic deformation predicted by TDEFNODE (blue arrows). The velocities estimated with the TDEFNODE model include the long-term velocity components estimated with the Chortis, Ipala and Fonseca block angular velocities and strain-rate tensors. They exclude the short-term elastic velocity component due to locked faults in the study area. The CA103P forward model successfully predicts the progressive increase in the magnitude and anticlockwise rotation of GPS site velocities from east to west despite imposing only three kinematic conditions on the finite element mesh (see Section 5.5). The CA103P predictions are limited to the subset of GPS sites that existed for the Rodriguez et al. (2009) study.

partitioning estimate is robust and that the plate boundary motion is dominated by slip on the Motagua fault.

\subsubsection{Fault locking depths}

Locking depths estimated in our preferred model range from 2.5$14 \mathrm{~km}$ for the Motagua fault and are consistently $5 \mathrm{~km}$ for the Polochic fault (Fig. 7a). Our most reliable estimate of the locking depth for the Motagua fault, a depth of $14 \mathrm{~km}$, is in its central region, where the well-distributed GPS sites clearly define the velocity gradient at all distances from the fault (Supporting Information Fig. S5b).

The locking depth estimates for the alternative models described in the Supporting Information range from 3 to $15 \mathrm{~km}$ for the Motagua fault and 5 to $15 \mathrm{~km}$ for the Polochic fault (Figs S11b-f in the Supporting Information). Due to the sparse GPS site coverage near both faults in most areas and fitting trade-offs between the fault locking depths and other adjustable model parameters, we consider the fault locking depths to be less reliably determined than the other model parameters.

\subsection{Central America forearc sliver: fits, fault slip rates and locking and robustness}

Destructive strike-slip earthquakes on faults within or near the Central America volcanic arc have occurred every several years during the past century (White 1991; White \& Harlow 1993), causing nearly 20000 fatalities since 1900 (White \& Harlow 1993). Rigorous estimates of the slip rates on these faults, which extend for $\approx 900 \mathrm{~km}$ in our study area, are an important objective of our study. All previously published elastic models of our study area approximate the lithosphere north of the Central America volcanic arc as a single, rigid Caribbean plate (Correa et al. 2009; Franco et al. 2012; Kobayashi et al. 2014), thereby limiting their utility for estimating any along-strike variations in the fault slip rates. In contrast, the slip rates estimated in our model can change along the volcanic arc via differential movements between the Caribbean, Chortis, Ipala and Motagua-Polochic blocks north of the arc (Fig. 5) and distributed deformation within the Chortis and Ipala blocks north of the arc and Fonseca block to its south.

The observations and model results related to the Central America forearc sliver are presented in several stages, beginning with brief descriptions of the observed GPS velocities and fits for data from the forearc sliver and concluding with short descriptions of the 
estimated slip rates and locking depths at key locations along the volcanic arc.

\subsubsection{Observations, fits and forearc sliver deformation}

The motion of the forearc sliver is constrained by 47 GPS sites on the sliver, 175 subduction zone earthquake slip directions, which are well fit by our preferred model (Fig. 4), three strike-slip fault azimuths (Section 2.2) and two a priori direction constraints for the Nicaraguan volcanic arc (Section 3.4). Relative to the Caribbean plate, the 47 GPS sites on the forearc sliver move at rates of 5$14 \mathrm{~mm} \mathrm{yr}^{-1}$ (Fig. 10a), generally increasing with distance from the volcanic arc (Supporting Information Figs S7 and S8). The GPS site directions are parallel to the coast and rotate anticlockwise from southeast to northwest along the coast (Fig. 10a). The fastest measured rates agree well with previous $12-16 \mathrm{~mm} \mathrm{yr}^{-1}$ estimates of the sliver motion (DeMets 2001; Lyon-Caen et al. 2006; CorreaMora et al. 2009; LaFemina et al. 2009; Alvarado et al. 2011; Kobayashi et al. 2014; Staller et al. 2016).

GPS velocity transects at six locations along the volcanic arc clearly indicate that the slip rates for faults in the arc vary along strike (Supporting Information Figs S7 and S8). Supporting Information Section S1.3 and Figs S7 and S8 describe and display the relevant GPS site velocities in more detail.

The velocities of the GPS sites along the volcanic arc are well fit by our preferred model (blue arrows in Figs 10-11 and blue circles in Supporting Information Figs S7 and S8). The $1.43 \mathrm{~mm} \mathrm{yr}^{-1}$ WRMS misfit for the 47 forearc site velocities is $\approx 40$ per cent larger than the $1.00 \mathrm{~mm} \mathrm{yr}^{-1}$ WRMS misfit for all 201 site velocities. The largerthan-average misfit for some GPS sites along the volcanic arc may be caused partly by the proximity of some sites to the volcanic arc faults, where the elastic model predictions are sensitive to the locations and orientations of the faults that we use to approximate the inland boundary of the forearc sliver. Specific examples are given below.

Our preferred model misfits the azimuths of the San Vicente, Berlin and San Miguel strike-slip segments in El Salvador by respective angles of $8.7^{\circ}, 2.1^{\circ}$ and $1.0^{\circ}$. Only the $8.7^{\circ}$ misfit to the San Vicente fault segment significantly exceeds its estimated $\pm 2^{\circ}$ uncertainty. We interpret the misfit as evidence that other structures adjacent to the San Vicente fault also accommodate some sliver motion.

As a test of the sliver rigidity, we derived a strain-rate tensor from the residual velocities of the 47 forearc sites. The maximum shortening axis of the residual strain-tensor is parallel to the trench and has a magnitude of only 0.3 nanostrains $\mathrm{yr}^{-1}$. The residual strain-rate tensor predicts an insignificant $0.2 \mathrm{~mm} \mathrm{yr}^{-1}$ of arc-parallel shortening integrated along the entire length of the forearc sliver in our study area. The forearc sliver thus does not appear to deform measurably along its length.

\subsubsection{Nicaragua}

The northwestwards, trench-parallel movement of the forearc sliver in Nicaragua is accommodated in most areas by bookshelf faulting along the volcanic arc across a zone that is several tens of kilometres wide (LaFemina et al. 2002; Funk et al. 2009). The slip rates estimated with our preferred model along the Nicaraguan volcanic arc decrease from $12.5 \pm 1.0 \mathrm{~mm} \mathrm{yr}^{-1}$ where the forearc sliver abuts the Caribbean plate to $10.4 \pm 1.2 \mathrm{~mm} \mathrm{yr}^{-1}$ where the sliver abuts the Chortis block (Fig. 7b). Although an $\approx 2 \mathrm{~mm} \mathrm{yr}^{-1}$ change in slip rate occurs at $86.6^{\circ} \mathrm{W}$, where the Chortis-Caribbean plate boundary intersects the volcanic arc (Fig. 5), the location and geometry of the Chortis-Caribbean plate boundary in Nicaragua are unknown due to the absence of any GPS sites in western Nicaraguan inland from the volcanic arc. The sudden change in the slip rate along the volcanic arc is thus an artefact of our Chortis block geometry in this area and is unlikely to be reliable. Our estimates of fault locking depths in Nicaragua are also unreliable given that bookshelf faulting rather than arc-parallel strike-slip faults accommodate forearc sliver motion at most locations (LaFemina et al. 2002; Funk et al. 2009).

\subsubsection{Fonseca block}

The Fonseca block, which occupies a $\approx 120$-km-wide step-over in the volcanic arc (Figs 5and 12), is bordered to the north by the San Miguel and Berlin segments of the El Salvador fault zone (Fig. 10b) and to its south, east and west by imprecisely known and likely diffuse boundaries. Fig. 12summarizes the fits, fault slip rates and strain-rate information for the Fonseca deforming block. The WRMS misfit for the eight Fonseca block GPS sites is $0.96 \mathrm{~mm} \mathrm{yr}^{-1}$, smaller than for the entire model $\left(1.00 \mathrm{~mm} \mathrm{yr}^{-1}\right)$. Significant misfits at most of the sites on and near the western half of the Fonseca block (Fig. 12) are due to our approximation of this wide deforming zone as a discrete boundary, despite our use of a strain-rate tensor to better fit the site velocities in this deforming region.

The motions across the northern (inland) and southern (trenchward) boundaries of the Fonseca block partition dextral motion between the forearc sliver and Chortis block (Fig. 12). The slip rates estimated for the well-defined inland boundary change rapidly from $9 \pm 2 \mathrm{~mm} \mathrm{yr}^{-1}$ at the western end of the Berlin segment to only $2 \pm 2 \mathrm{~mm} \mathrm{yr}^{-1}$ at the eastern end of the San Miguel segment (Fig. 12). Slip rates estimated for the southern boundary also change rapidly from $1.2 \pm 3.9 \mathrm{~mm} \mathrm{yr}^{-1}$ in southeastern El Salvador to 9.0 $\pm 2.8 \mathrm{~mm} \mathrm{yr}^{-1}$ at the boundary's eastern terminus (Fig. 12). These rapid changes are due almost entirely to the rapid internal deformation of the block. The block strain-rate tensor (Table 2) predicts an elongation rate of $12 \pm 6 \mathrm{~mm} \mathrm{yr}^{-1}$ integrated across the $\approx 100-\mathrm{km}^{-}$ wide block. This exceeds by a factor-of-two the slip rates due to the block's rotation. The existence of numerous, N-S-striking normal faults in eastern El Salvador (Alvarado et al. 2011) suggests that the strain-rate tensor, which predicts that the block deformation is dominated by E-W stretching, is accurate.

\subsubsection{El Salvador}

The forearc sliver motion in El Salvador is accommodated by the well-defined San Vicente, Lempa, Berlin and San Miguel strikeslip segments (Fig. 10b) and by distributed normal- and bookshelf faulting within the pull-apart basins that connect these strike-slip fault segments (Corti et al. 2005; Agostini et al. 2006; Funk et al. 2009; Alvarado et al. 2011; Canora et al. 2012; Garibaldi et al. 2016). Our model predicts a slip rate of $10.3 \pm 1.2 \mathrm{~mm} \mathrm{yr}^{-1}$ along the San Vicente fault segment in eastern El Salvador, but only $9.7 \pm$ $1.4 \mathrm{~mm} \mathrm{yr}^{-1}$ in western El Salvador (Fig. 7b). The small difference in the estimated slip rates is due to Chortis block extension north of the volcanic arc, which is subparallel to the volcanic arc faults (Fig. 7b).

Our preferred model fits most of the GPS site velocities in central and western El Salvador within their estimated uncertainties (blue arrows in Figs 10and 11and blue circles in Figs S7 and S8 of the 
Supporting Information). Significant misfits at some sites, including continuous sites SNJE and CNR1 (Fig. 10b and Fig. S8a of the Supporting Information), occurs in areas where bookshelf faulting, normal faulting and strike-slip faulting accommodate the forearc motion in a poorly understood manner.

Locking depths that are estimated for the volcanic arc faults in El Salvador are typically 2.5 to $5 \mathrm{~km}$ (Fig. $7 \mathrm{a}$ ), consistent with $4-9 \mathrm{~km}$ locking depths estimated by Staller et al. (2016) from 1-D modelling of a subset of these observations. A 1-D forward elastic half-space model in which locking is assumed to extend downwards to a depth of $15 \mathrm{~km}$ systematically misfits the velocities of sites in a transect of central El Salvador (dashed grey line in Fig. S7c of the Supporting Information). Locking as deep as $15 \mathrm{~km}$ for the volcanic arc faults thus can be excluded with some confidence.

\subsubsection{Guatemala: Jalpatagua fault and the western volcanic arc}

The motion of the forearc sliver in southern Guatemala is accommodated by the little-studied Jalpatagua fault (located in Fig. 10b), which is the westernmost mapped strike-slip fault in the volcanic arc (Carr 1976; Wunderman \& Rose 1984; Authemayou et al. 2011). Earthquakes on normal faults that are well expressed in the topography immediately south of the Jalpatagua fault, including some with normal-faulting focal mechanisms (Fig. 10b), indicate that the forearc sliver motion is partitioned between the Jalpatagua fault and other nearby faults.

A comparison of the velocities of GPS sites from transects of the volcanic arc faults in central and western El Salvador (Supporting Information Figs S7c and 8a) to those from a transect of the Jalpatagua fault (Supporting Information Fig. S8b) clearly indicates that the slip rate is slower for the latter than the former. Our model predicts forearc sliver motion along the Jalpatagua fault of $7.6 \pm$ $2.1 \mathrm{~mm} \mathrm{yr}^{-1}$ towards $\mathrm{N} 75^{\circ} \mathrm{W} \pm 12^{\circ}$ (Fig. $7 \mathrm{~b}$ ), which resolves into $7.5 \pm 2.1 \mathrm{~mm} \mathrm{yr}^{-1}$ fault-parallel and $1 \pm 1.5 \mathrm{~mm} \mathrm{yr}^{-1}$ fault-normal slip-rate components for the $\mathrm{N} 65-68^{\circ} \mathrm{W}$-striking fault. The five alternative models described in our Supporting Information variously predict Jalpatagua fault slip rates of 6.3 to $9.8 \mathrm{~mm} \mathrm{yr}^{-1}$ (Supporting Information Figs S12 and S13). Our $7.6 \pm 2.1 \mathrm{~mm} \mathrm{yr}^{-1}$ preferred slip rate estimate and its 95 per cent uncertainty are thus robust with respect to the range of models that we explored.

Along the volcanic arc west of its intersection with the Guatemala City graben, where our block geometry includes a boundary between the forearc sliver and the Motagua-Polochic block (Fig. 5), no well-defined faults or other structures unambiguously define an inland boundary for the forearc sliver. The lack of any discernible velocity gradient for the GPS sites that cross the volcanic arc west of Guatemala City (Supporting Information Fig. S8c) suggests an upper limit of only $2-3 \mathrm{~mm} \mathrm{yr}^{-1}$ for any arc-parallel component of motion west of the Guatemala City graben. The angular velocity for the forearc sliver relative to the Motagua-Polochic block (Table 1) predicts obliquely convergent motion across the arc at rates of only $1.4-3.0 \pm 1.5 \mathrm{~mm} \mathrm{yr}^{-1}$ (Fig. 7b). The predicted slowdown in the forearc sliver motion from $7.6 \pm 2.1 \mathrm{~mm} \mathrm{yr}^{-1}$ at the Jalpatagua fault to only $1.4-3 \mathrm{~mm} \mathrm{yr}^{-1}$ west of the Guatemala City graben is accommodated via a northward transfer of the slip at the western terminus of the Jalpatagua fault into the Guatemala City graben and possibly other nearby normal faults.

\section{DISCUSSION}

Our new velocity field and its best-fitting elastic model have broad implications given the complexity of the deformation in our study area. Below, we focus on the implications that are relevant for assessments of earthquake hazard on the Middle America trench, for fault slip rates and earthquake hazards for the major strike-slip faults in our study area, for the interrelationships between deformation in the Chortis extensional zone and strike-slip motions along the bordering Motagua fault and Central America volcanic arc and for the forces that dictate the regional deformation.

\subsection{Reconciling low subduction locking with the $2012 \mathrm{El}$ Salvador megathrust earthquake}

Prior to the $M_{\mathrm{w}}=7.32012$ El Salvador subduction-thrust earthquake, the last notable subduction-thrust earthquake to rupture the El Salvador trench segment was in 1915 and possibly earlier (White et al. 2004). The coseismic slip estimated for the 2012 earthquake from modelling of the coseismic offsets measured at GPS sites onshore from the earthquake averaged only 500-800 $\mathrm{mm}$ (Geirsson et al. 2015; Ellis et al. 2018). For comparison, our newly estimated Cocos-forearc sliver angular velocity (Table 1) predicts that the cumulative plate convergence was $\approx 7300 \mathrm{~mm}$ between 1915 and 2012 at the 2012 earthquake location. The implied seismic locking ratio is thus only 7 to 11 per cent and is even smaller if the 1915 earthquake was not a thrust earthquake. Our elastic modelling gives an $\approx 16$ per cent average locking ratio for areas offshore from Guatemala, El Salvador and Nicaragua (Fig. 7a), consistent with the low seismic locking ratio.

If large-magnitude thrust earthquakes occur infrequently along the El Salvador trench segment, as is indicated by the low seismic and geodetic locking ratios, then aseismic processes such as creep, earthquake afterslip and episodic silent slip events must accommodate most of the subduction ( 85 per cent or more). Episodic silent slip events have not yet been reported for this trench segment; however, widespread, large-magnitude afterslip following the 2012 earthquake is qualitatively consistent with low locking of the subduction interface (Ellis et al. 2018). Intraslab normal-faulting earthquakes such as the $M_{\mathrm{w}}=7.31982$ and $M_{\mathrm{w}}=7.82001$ earthquakes below El Salvador (Martinez-Diaz et al. 2004; Guzman-Speziale et al. 2005; Correa-Mora et al. 2009) and upper-plate strike-slip earthquakes that may be triggered by the intraslab normal-faulting events (Martinez-Diaz et al. 2004) may be the principal earthquake hazards along the El Salvador trench segment.

\subsection{Comparison to geological observations and implications}

Long-term fault slip rates estimated with our new model compare favourably with slip rates that have been estimated from geological studies of several faults in our study area. Authemayou et al. (2012) use cosmogenic ${ }^{36} \mathrm{Cl}$ surface exposure dating of Quaternary volcanic markers and alluvial fans that are offset along the central portion of the Polochic fault to estimate a $4.8 \pm 2.3 \mathrm{~mm} \mathrm{yr}^{-1}$ Holocene slip rate. Their slip rate estimate agrees within its ucertainties with an independent $2.5-3.3 \mathrm{~mm} \mathrm{yr}^{-1}$ geological estimate that is based on the $25-\mathrm{km}$ tectonic deflection of the Chixoy River over the past 7.5-10 Myr (Brocard et al. 2011). Both slip rates agree with our $3.3 \pm 1.3 \mathrm{~mm} \mathrm{yr}^{-1}$ geodetic estimate (Figs $7 \mathrm{~b}$ ). In contrast, Burkart (1978), Burkart (1983) and Burkart et al. (1987) estimate a $123-132 \mathrm{~km}$ sinistral offset for the Polochic fault, most likely 
since the late Miocene (11.6-5.3 Ma). If the offset occurred since $11.6 \mathrm{Ma}$, the implied average slip rate of $\approx 11 \mathrm{~mm} \mathrm{yr}^{-1}$ is three times faster than our geodetic estimate.

Along the Motagua fault, measurements of offset Quaternary stream terraces give a maximum slip rate of $\approx 6 \mathrm{~mm} \mathrm{yr}^{-1}$ (Schwartz et al. 1979), less than half our $13-14 \pm 1.6 \mathrm{~mm} \mathrm{yr}^{-1}$ geodetic estimate (Fig. 7b). More work is needed to resolve this apparent discrepancy.

Along the Berlin segment of the El Salvador Fault Zone, Corti et al. (2005) estimate a minimum slip rate of $11 \mathrm{~mm} \mathrm{yr}^{-1}$ slip rate from offsets of a paleosurface and drainages. At the same location, our estimated slip rates are 9-10 $( \pm 2.0) \mathrm{mm} \mathrm{yr}^{-1}$ (Fig. 12), the same within the uncertainties. Along the Lempa and San Vicente fault segments (Fig. 7b), where our preferred model predicts a fault slip rate of $9.9 \pm 1.4 \mathrm{~mm} \mathrm{yr}^{-1}$, Canora et al. (2012) estimate a $4.1 \pm 0.7 \mathrm{~mm} \mathrm{yr}^{-1}$ late Pleistocene-Holocene slip rate from fault trenching data and Canora et al. (2014) estimate a geological slip rate of $4.5 \pm 0.6 \mathrm{~mm} \mathrm{yr}^{-1}$ from geological offsets, paleoseismic analysis and a river offset. Both interpret the factorof-two slower geological estimates as evidence that slip is either distributed across multiple faults in the volcanic arc or that their estimates are in error due to volcanic activity and/or high erosion rates.

\subsection{The Chortis extensional zone: comparisons to geologic and seismic constraints}

The deformation predicted by our new model for the triangular Chortis extensional zone can be compared to geologically and seismologically derived estimates of the directions and rates of presentday and longer term deformation in this region. Spanning the Neogene, Gordon \& Muehlberger (1994) propose that the Chortis block has moved mostly northward based on their interpretation of geologic maps, remote imagery and seismic data. Our observations and best-fitting elastic model instead show that the Chortis and Ipala blocks move generally westwards away from the Caribbean plate at respective rates of 2-3 and $6 \mathrm{~mm} \mathrm{yr}^{-1}$ (Fig. 8b).

From a geomorphologic analysis, Rogers \& Mann (2007) interpret Chortis block deformation to consist mostly of $\approx \mathrm{E}-\mathrm{W}$ rifting, with more active rifting in the western than the eastern part of the Chortis extensional zone. Our observations and modelling support their interpretation. Our analysis indicates that distributed deformation within the Chortis and Ipala blocks is statistically significant, is dominated by ENE-to-WSW extension in both blocks and has principal extensional strain rates that are larger in the western than the eastern portion of the extending zone (Figs 6-8).

Spanning much shorter timescales, Guzman-Speziale (2001) and Caceres et al. (2005) estimate integrated $\approx \mathrm{E}-\mathrm{W}$ elongation rates of $3-8 \mathrm{~mm} \mathrm{yr}^{-1}$ across the grabens of Honduras and southern Guatemala from summed seismic moment tensors for historical and modern earthquakes in Central America. For the same region, our preferred model predicts a net long-term east-west elongation rate of $6.4 \pm 2 \mathrm{~mm} \mathrm{yr}^{-1}$. The geodetic and seismic estimates are thus consistent.

\subsection{Volcanic arc and Motagua fault slip-rate changes and slip termination}

From east to west along the Motagua fault and volcanic arc, our new model implies that progressively more slip is transferred into the
Chortis extensional zone southwards from the Motagua fault and northwards from the volcanic arc faults. The largest predicted transfers of slip into the Chortis extensional zone occur at the Guatemala City graben, where our simple model predicts that all the remaining $8-9 \mathrm{~mm} \mathrm{yr}^{-1}$ of slip on the Jalpatagua and Motagua faults is transferred into the graben (Figs $6 \mathrm{~b}$ and $7 \mathrm{~b}$ ). As discussed in Section 4.6.2, the slip on these two faults does not terminate abruptly at their intersections with the Guatemala City graben, but instead terminates gradually west of their intersections as the slip on both faults is transferred onto the NE-striking normal faults west of Guatemala City between the Motagua fault and volcanic arc.

West of $91.15^{\circ} \mathrm{W}(\approx 70 \mathrm{~km}$ west of Guatemala City), the morphologic expression of the Motagua fault disappears. From the velocities of campaign and continuous GPS sites that we installed on both sides of the Motagua fault in this region (Figs $6 \mathrm{~b}$ and c), we estimate a firm upper bound of $1.5 \mathrm{~mm} \mathrm{yr}^{-1}$ for any sinistral shear west of $91.15^{\circ} \mathrm{W}$, where the fault trace disappears. Specifically, continuous GPS sites TECP and QUE1 south of the Motagua fault (Fig. 6c) move to the west at $12.8-12.9 \mathrm{~mm} \mathrm{yr}^{-1}$, systematically slower than the $14.0-14.7 \mathrm{~mm} \mathrm{yr}^{-1}$ westward motions of campaign sites JOY0, QICH and TOTO north of the Motagua fault. Future measurements at these sites are needed to determine whether the small, but persistent difference in the fault-parallel component of the station motions is evidence for a westward continuation of slow sinistral shear within the interior of the Motagua-Polochic block west of the Guatemala City graben.

\subsection{Forces that determine the regional deformation}

Alvarez-Gomez et al. (2008) use a finite element mesh (FEM) with the major faults in our study area to evaluate how different assumed boundary and faulting conditions influence the long-term regional deformation for a mesh driven by Caribbean-North America plate motion. They find that FEMs with low or no locking of the subduction interface, a rheologically weak volcanic arc and a forearc sliver that moves slowly or not at all relative to the North America plate predict regional strain-rate tensors with principal axes that match those derived from earthquake focal mechanisms. Using similar methods, Rodriguez et al. (2009) show that strike-slip motion along the arcuate trace of the Motagua fault is a necessary condition for matching GPS site velocities from Honduras.

Fig. 13compares the long-term component of GPS site velocities estimated from our model and observations (i.e. the velocity component that remains after subtracting the interseismic elastic velocity component estimated by TDEFNODE) to the velocities predicted by FEM model 103P of Rodriguez et al. (2009), which satisfies all of the conditions outlined above. The directions predicted by the FEM closely match the estimated long-term site directions at nearly all locations (Fig. 13). For example, the gradual $60^{\circ}$ eastto-west anticlockwise change in the site directions predicted by the FEM (red arrows in Fig. 13) closely matches the $53^{\circ}$ anticlockwise change in the long-term directions estimated from our TDEFNODE inversion (black arrows in Fig. 13). The FEM-modelled site rates agree closely with those estimated with TDEFNODE in the southern and western areas of the modelled region, including the westernmost site GUAT (labelled in Fig. 13). The FEM-predicted site rates are, however, significantly faster than our TDEFNODE estimates at most locations north of $14.6^{\circ} \mathrm{N}$.

Overall, the long-term velocities from our TDEFNODE inversion and those determined by Rodriguez et al. (2009) via forward modelling of the regional deformation agree well enough to suggest 
that some or possibly most of the assumptions and constraints that were incorporated in the FEM modelling are correct.

\section{CONCLUSIONS}

The interseismic velocities of more than 200 continuous and campaign GPS stations from northern Central America and southern Mexico reveal in unprecedented detail the active deformation of this complexly deforming region, where eight distinct plates and blocks, some deforming internally, interact to accommodate plate motions at the western end of the Caribbean plate. Highlights of the new velocity field and its best-fitting elastic block model are as follows:

(1) GPS sites in the seismically active region of central/western Honduras and southern Guatemala between the Motagua fault and Central America volcanic arc, where the morphology is dominated by N-S-trending basins and ranges, move slowly to the WNW away from the Caribbean plate at rates that increase gradually from 1$2 \mathrm{~mm} \mathrm{yr}^{-1}$ in central Honduras to $5 \mathrm{~mm} \mathrm{yr}^{-1}$ at the Guatemala City graben (Figs $6 \mathrm{~b}$ and $8 \mathrm{~b}$ ).

(2) Our best-fitting elastic block model, which subdivides the Chortis extensional zone into Chortis and Ipala blocks (Fig. 5), predicts that the two blocks move to the WNW away from the Caribbean plate at respective average rates of $2.4 \pm 0.7$ and $6.1 \pm 1.7 \mathrm{~mm} \mathrm{yr}^{-1}$ and further predicts respective, integrated elongation rates of 1.8 $\pm 0.9 \mathrm{~mm} \mathrm{yr}^{-1}$ and $5 \pm 2 \mathrm{~mm} \mathrm{yr}^{-1}$ and principal elongation axes oriented $\approx$ ENE-WSW across the two blocks.

(3) Our preferred elastic model indicates that the motion of the Chortis block relative to North America averages $18 \pm 1 \mathrm{~mm} \mathrm{yr}^{-1}$ in eastern Guatemala, of which the Motagua and Polochic faults, respectively, accommodate 80 per cent and 20 per cent of the plate motion.

(4) GPS velocity transects of the Motagua fault in eastern Guatemala, central Guatemala and immediately west of the Guatemala City graben show that the fault slip rate decreases from $14.2 \pm 1.5$ to $9-10 \pm 2 \mathrm{~mm} \mathrm{yr}^{-1}$ to under $2 \mathrm{~mm} \mathrm{yr}^{-1}$ for the three transects. The progressive westward slowdown in the fault slip rates occurs as motion is transferred from the fault southwards into the Chortis extensional zone.

(5) GPS velocity transects of the Central America volcanic arc indicate that the rate of dextral motion of the forearc sliver parallel to the volcanic arc decreases from a maximum of $12.5 \pm 1.0 \mathrm{~mm} \mathrm{yr}^{-1}$ in Nicaragua to $7.6 \pm 2.1 \mathrm{~mm} \mathrm{yr}^{-1}$ along the Jalpatagua fault of southern Guatemala and not more than $2-3 \mathrm{~mm} \mathrm{yr}^{-1}$ along the arc west of Guatemala City. The progressive slowdown occurs as slip is transferred northwards from the volcanic arc faults into the Chortis extensional zone.

(6) Our observations and modelling indicate that the Guatemala City graben and a series of normal faults immediately to its west are a major tectonic discontinuity, across which $8 \mathrm{~mm} \mathrm{yr}^{-1}$ of largely E-W divergence is distributed across a zone not wider than $60 \mathrm{~km}$ (Fig. 6b).

(7) Our elastic model identifies with high confidence a transition from moderate-to-high locking along the Cocos-North America subduction interface offshore from southern Mexico to low locking across the Cocos-forearc sliver subduction interface offshore southern Guatemala, El Salvador and northwestern Nicaragua.

(8) The angular velocity that specifies Cocos plate-forearc sliver motion offshore El Salvador, Guatemala and Nicaragua predicts that subduction is up to $10 \mathrm{~mm} \mathrm{yr}^{-1}$ faster than and $7-8^{\circ}$ clockwise from previous estimates of Middle America trench convergence velocities.

(9) The newly defined Fonseca block of eastern El Salvador and the adjacent Gulf of Fonseca accommodates $\approx 12 \mathrm{~mm} \mathrm{yr}^{-1}$ of distributed E-W extension within its interior and rotates about nearby poles relative to the neighbouring Chortis and forearc sliver blocks, giving rise to rapid changes in fault slip rates along its boundaries (Fig. 12).

(10) The largest model misfits occur in areas of northern Guatemala and southern Mexico, where structural and seismic data define a region of distributed upper plate deformation. Further work is needed to determine whether accounting for viscoelastic earthquake cycle effects and/or upper-plate deformation in this region resolves the coherent pattern of misfits.

\section{ACKNOWLEDGEMENTS}

The first author was supported by a UNAVCO Graduate COCONet Fellowship. This work was funded by NSF grant EAR-1144418 (DeMets). Some of this material is based on services provided by Continuously Operating Caribbean GPS Observational Network: Infrastructure for a Multi-hazard Tectonic and Weather Observatory (COCONet), supported by the National Science Foundation under EAR-1042906. We thank Central American institutions that provided technical, data and logistical support, including Universidad Nacional Autonoma de Honduras, Universidad Nacional Autonoma de Mexico, Universidad Mariano Galvez (Guatemala City), Universidad San Carlos (Guatemala City), Ministerios de Medio Ambiente y Recursos Naturales El Salvador, Instituto Geografico Nacional of El Salvador and Guatemala, INSIVUMEH of Guatemala and CONRED of Guatemala. We also thank Dave Mencin of UNAVCO and Hector Mora Paez of Servicio Geologico Colombiano for providing daily positions from the continuous Colombian GPS site CAYS in the western Caribbean Sea. Figures were prepared using Generic Mapping Tools software (Wessel \& Smith 1991).

\section{REFERENCES}

Agostini, S. et al., 2006. Tectonic and magmatic evolution of the active volcanic front in El Salvador: insight into the Berlin and Ahuachapan geothermal areas, Geothermics, 35, 368-408.

Altamimi, Z., Collilieux, X. \& Metivier, L., 2011. ITRF2008: an improved solution of the international terrestrial reference frame, J. Geod., 8, 457473.

Alvarado, D. et al., 2011. Forearc motion and deformation between El Salvador and Nicaragua: GPS, seismic, structural, and paleomagnetic observations, Lithosphere, 3, 3-21.

Alvarez-Gomez, J.A., Meijer, P.T., Martinez-Diaz, J.J. \& Capote, R., 2008. Constraints from finite element modeling on the active tectonics of northern Central America and the Middle America Trench, Tectonics, 27, TC1008, doi:10.1029/2007TC002162.

Andreani, L. \& Gloaguen, R., 2016. Geomorphic analysis of transient landscapes in the Sierra Madre de Chiapas and Maya Mountains (northern Central America): implications for the North American-Caribbean-Cocos plate boundary, Earth Surf. Dyn., 4, 71-102.

Authemayou, C., Brocard, G., Teyssier, C., Simon-Labric, T., Guttierrez, A., Chiquin, E.N. \& Moran, S., 2011. The Caribbean-North America-Cocos triple junction and the dynamics of the Polochic-Motagua fault systems: pull-up and zipper models, Tectonics, 30, TC3010, doi:10.1029/2010TC002814.

Authemayou, C. et al., 2012. Quaternary seismo-tectonic activity of the Polochic Fault, Guatemala, J. geophys. Res., 117, B07403, doi:10.1029/2012JB009444. 
Benford, B., DeMets, C. \& Calais, E., 2012. GPS estimates of microplate motions, northern Caribbean: evidence for a Hispaniola microplate and implications for earthquake hazard, Geophys. J. Int., 191, 481-490.

Brocard, G., Teyssier, C., Dunlap, W.J., Authemayou, C., Simon-Labric, T., Cacao-Chiquin, E.N., Gutierrez-Orrego, A. \& Moran-Ical, S., 2011. Reorganization of a deeply incised drainage: role of deformation, sedimentation, and groundwater flow, Basin Res., 23, 631-651.

Burkart, B., 1978. Offset across the Polochic fault of Guatemala and Chiapas, Mexico, Geology, 6, 328-332.

Burkart, B., 1983. Neogene North American-Caribbean plate boundary: offset along the Polochic fault, Tectonophys., 99, 251-270.

Burkart, B., Deaton, B.C., Dengo, C. \& Moreno, G., 1987. Tectonic wedges and offset Laramide structures along the Polochic fault of Guatemala and Chiapas, Mexico: reaffirmation of large Neogene displacement, Tectonics, 6, 411-422.

Caceres, D., Monterroso, D. \& Tavakoli, B., 2005. Crustal deformation in northern Central America, Tectonophys., 404, 119-131.

Canora, C., Villamor, P., Martinez-Diaz, J. J., Berryman, K. R., AlvarezGomez, J.A., Capote, R. \& Hernandez, W., 2012. Paleoseismic analysis of the San Vicente segment of the El Salvador Fault Zone, El Salvador, Central America, Geologica Acta, 10, 103-123.

Canora, C., Martinez-Diaz, J.J., Villamor, P., Staller, A., Berryman, K., Alvarez-Gomez, J.A., Capote, R. \& Diaz, M., 2014. Structural evolution of the El Salvador Fault Zone: an evolving fault system within a volcanic arc, J. Iberian Geol., 40, 471-488.

Carr, M.J., 1976. Underthrusting and Quaternary faulting in northern Central America, Bull. geol. Soc. Am., 87, 825-829.

Correa-Mora, F. et al., 2009. GPS-derived coupling estimates for the Central America subduction zone and volcanic arc faults: El Salvador, Honduras, and Nicaragua, Geophys. J. Int., 179, 1279-1291.

Corti, G., Carminati, E., Mazzarini, F. \& Garcia, M.O., 2005. Active strikeslip faulting in E1 Salvador, Central America, Geology, 33, 989-992.

DeMets, C., 2001. A new estimate for present-day Cocos-Caribbean plate motion: implications for slip along the Central American volcanic arc, Geophys. Res. Lett., 28, 4043-4046.

DeMets, C., Mattioli, G., Jansma, P., Rogers, R., Tenorio, C. \& Turner, H.L., 2007. Present motion and deformation of the Caribbean plate: Constraints from new GPS geodetic measurements from Honduras and Nicaragua, in Geologic and Tectonic Development of the Caribbean Plate in Northern Central America, Vol. 428, pp. 21-36, ed. Mann, P., Geol. Soc. Am. Spec. Paper, The Geological Society of America, Boulder.

DeMets, C., Gordon, R.G. \& Argus, D.F., 2010. Geologically current plate motions, Geophys. J. Int., 181, 1-80.

Dziewonski, A.M., Chou, T.-A. \& Woodhouse, J.H., 1981. Determination of earthquake source parameters from waveform data for studies of global and regional seismicity, J. geophys. Res., 86, 2825-2852.

Ekstrom, G., Nettles, M. \& Dziewonski, A.M., 2012. The global CMT project 2004-2010: centroid-moment tensors for 13,017 earthquakes, Phys. Earth planet. Int., 200-201, 1-9.

Ellis, A. et al., 2018. GPS constraints on deformation in northern Central America from 1999 to 2017, Part 1 - Time-dependent modelling of large regional earthquakes and their post-seismic effects, Geophys. J. Int., 214, 2177-2194.

Franco, A. et al., 2012. Fault kinematics in northern Central America and coupling along the subduction interface of the Cocos plate, from GPS data in Chiapas (Mexico), Guatemala, and El Salvador, Geophys. J. Int., 189, 1223-1236.

Funk, J., Mann, P., McIntosh, K. \& Stephens, J., 2009. Cenozoic tectonics of the Nicaraguan depression, Nicaragua, and Median Trough, El Salvador, based on seismic-reflection profiling and remote-sensing data, Bull. geol. soc. Am., 121, 1491-1521.

Garibaldi, N., Tikoff, B. \& Hernandez, W., 2016. Neotectonic deformation within an extensional stepover in El Salvador magmatic arc, Central America: implication for the interaction of arc magmatism and deformation, Tectonophys, 693, 327-339.
Geirsson, H. et al., 2015. The 2012 August $27 M_{\mathrm{w}} 7.3$ El Salvador earthquake: expression of weak coupling on the Middle America subduction zone, Geophys. J. Int., 202, 1677-1689.

Gordon, M.B. \& Muehlberger, W.R., 1994. Rotation of the Chortis block causes dextral slip on the Guayupe fault, Tectonics, 13, 858-872.

Guzman-Speziale, M., 2001. Active seismic deformation in the grabens of northern Central America and its relationship to the relative motion of the North America-Caribbean plate boundary, Tectonophys, 337, 39-51.

Guzman-Speziale, M., 2010. Beyond the Motagua and Polochic faults: active strike-slip faulting along the Western North America-Caribbean plate boundary zone, Tectonophys., 496, 17-27.

Guzman-Speziale, M. \& Meneses-Rocha, J.J., 2000. The North AmericaCaribbean plate boundary west of the Motagua-Polochic fault system: a fault jog in southeastern Mexico, J. S. Am. Earth Sci., 13, 459-468.

Guzman-Speziale, M. \& Gomez-Gonzalez, J.M., 2006. Seismic strain rate along the Middle America Trench reveals significant differences between Cocos-North America and Cocos-Caribbean convergence, Geophys. J. Int., 166, 179-185.

Guzman-Speziale, M. \& Zuniga, F.R., 2016. Differences and similarities in the Cocos-North America and Cocos-Caribbean convergence, as revealed by seismic moment tensors, J. S. Am. Earth Sci., 71, 296-308.

Guzman-Speziale, M., Pennington, W.D. \& Matumoto, T., 1989. The triple junction of the North America, Cocos, and Caribbean plates: Seismicity and tectonics, Tectonics, 8, 981-997.

Guzman-Speziale, M., Valdes-Gonzalez, C., Gomez, J.M. \& Molina, E., 2005. Seismic activity along the Central America volcanic arc: Is it related to subduction of the Cocos plate?, Tectonophys, 400, 241-254.

Harlow, D.H. \& White, R.A., 1985. Shallow earthquakes along the volcanic chain in Central America: evidence for oblique subduction, Earthq. Notes, $\mathbf{5 5}, 28-28$.

Hayes, G.P., Wald, D.J. \& Johnson, R.L., 2012. Slab1.0: a three-dimensional model of global subduction zone geometries, J. geophys. Res., 117, doi:10.1029/2011JB008524.

Hayes, G.P., Moore, G.L., Portner, D.E., Hearne, M., Flamme, H., Furtney, M. \& Smoczyk, G.M., 2018. Slab2, a comprehensive subduction zone geometry model, Science, 362, 58-61.

Kobayashi, D., LaFemina, P., Geirsson, H., Chichaco, E., Abrego, A.A., Mora, H. \& Camacho, E., 2014. Kinematics of the western Caribbean plate: collision of the Cocos Ridge and upper plate deformation, Geochem. Geophys. Geosys., 15, 1671-1683.

LaFemina, P.C., Dixon, T.H. \& Strauch, W., 2002. Bookshelf faulting in Nicaragua, Geol. soc. Am. Bull., 30, 751-754.

LaFemina, P. et al., 2009. Fore-arc motion and Cocos Ridge collision in Central America, Geochem. Geophys. Geosys., 10, Q05S14, doi:10.1029/2008GC002181.

Langer, C.J. \& Bollinger, G.A., 1979. Secondary faulting near the terminus of a seismogenic strike-slip fault: aftershocks of the 1976 Guatemala earthquake, Bull. seism. Soc. Am., 69, 427-444.

Li, S., Moreno, M., Bedford, J., Rosenau, M. \& Oncken, O., 2015. Revisiting viscoelastic effects on interseismic deformation and locking degree: a case study of the Peru-North Chile subduction zone, J. geophys. Res., 120, 4522-4538.

Lyon-Caen, H. et al., 2006. Kinematics of the North American-CaribbeanCocos plates in Central America from new GPS measurements across the Polochic-Motagua fault system, Geophys. Res. Lett., 33.

Martinez-Diaz, J.J., Alvarez-Gomez, J.A., Benito, B. \& Hernandez, D., 2004. Triggering of destructive earthquakes in El Salvador, Geology, 32, 65-68.

McCaffrey, R., 2002. Crustal block rotations and plate coupling, in Plate Boundary Zones, Vol. 30, pp. 101-122, eds Stein, S. \& Freymueller, J.T., Am. Geophys. Un., Washington, DC.

McCaffrey, R., 2005. Block kinematics of the Pacific-North America plate boundary in the southwestern United States from inversion of GPS, seismological, and geologic data, J. geophys. Res., 110, B07401, doi:10.1029/2004JB003307.

McCaffrey, R., 2009. Time-dependent inversion of three-component continuous GPS for steady and transient sources in northern Cascadia, Geophys. Res. Lett., 36, L07304, doi:10.1029/2008GL036784. 
Molnar, P. \& Sykes, L.R., 1969. Tectonics of the Caribbean and Middle America regions from focal mechanisms and seismicity, Geol. soc. Am. Bull., 80, 1639-1684.

Plafker, G., 1976. Tectonic aspects of the Guatemala earthquake of 4 February 1976, Science, 193, 1201-1208.

Rodriguez, M., DeMets, C., Rogers, R., Tenorio, C. \& Hernandez, D., 2009. A GPS and modelling study of deformation in northern Central America, Geophys. J. Int., 178, 1733-1754.

Rogers, R.D. \& Mann, P., 2007. Transtensional deformation of the western Caribbean-North America plate boundary zone, in Geologic and Tectonic Development of the Caribbean Plate Boundary in Northern Central America, pp. 37-64, ed. Mann, P., Geol. Soc. Am. Spec. Paper 428, Geol. Soc. Am., Boulder.

Rosencrantz, E. \& Mann, P., 1991. SeaMARC II mapping of transform faults in the Cayman Trough, Caribbean Sea, Geology, 19, 690-693.

Schwartz, D.P., Cluff, L.S. \& Donnelly, T.W., 1979. Quaternary faulting along the Caribbean-North American plate boundary in Central America, Tectonophys., 52, 432-445.

Staller, A., Martinez-Diaz, J.J., Benito, B., Alonso-Henar, J., Hernandez, D., Hernandez-Rey, R. \& Diaz, M., 2016. Present-day crustal deformation along the El Salvador Fault Zone from ZFESNet GPS network, Tectonophys., 670, 66-81.

Symithe, S., Calais, E., de Chabalier, J.B., Robertson, R. \& Higgins, M., 2015. Current block motions and strain accumulation on active faults in the Caribbean, J. geophys. Res., 120, 3748-3774.

Turner, H.L.I., LaFemina, P., Saballos, A., Mattioli, G.S., Jansma, P.E. \& Dixon, T., 2007. Kinematics of the Nicaraguan forearc from GPS geodesy, Geophys. Res. Lett., 34, L02302, doi:10.1029/2006GL027586.

Wessel, P. \& Smith, W.H.F., 1991. Free software helps map and display data, EOS Trans. Am. geophys. Un., 72, 441-446.

Weyl, R., 1980. Geology of Central America, in Beitrage Zur Regionalen Geologie der Erde, Vol. 15, p. 371, Gebruder Borntraeger Verlagsbuchhandlung, Berlin.

White, R.A., 1985. The Guatemala earthquake of 1816 on the ChixoyPolochic fault, Bull. seism. Soc. Am., 75, 455-473.

White, R.A., 1991. Tectonic implications of upper-crustal seismicity in Central America, in Neotectonics of North America, Decade Map, Vol. 1, pp. 323-328, eds Slemmons, D.B., Engdahl, E.R., Zoback, M.D. \& Blackwell, D.D., Geol. Soc. Am., Boulder.

White, R.A. \& Harlow, D.H., 1993. Destructive upper-crustal earthquakes of Central America since 1900, Bull. seism. Soc. Am., 83, 1115-1142.

White, R.A., Ligorria, J.P. \& Cifuentes, I.L., 2004. Seismic history of the Middle America subduction zone along El Salvador, Guatemala, and Chiapas, Mexico: 1526-2000, in Natural Hazards in El Salvador, Vol. 375, pp. 379-396, eds Rose, W.I., Bommer, J.J., Lopez, D.L., Carr, M.J. \& Major, J.J., Geol. Soc. Am. Spec. Paper, Boulder, CO.

Witt, C., Rangin, C., Andreani, L., Olaez, N. \& Martinez, J., 2012. The transpressive left-lateral Sierra Madre de Chiapas and its buried front in the Tabasco plain (southern Mexico), J. geol. Soc. Lond., 169, 143-155.

Wunderman, R.L. \& Rose, W.I., 1984. Amatitlan, an active resurging cauldron $10 \mathrm{~km}$ south of Guatemala City, J. geophys. Res., 89, 8525-8539.

\section{SUPPORTING INFORMATION}

Supplementary data are available at GJI online.

Figure S1. (a) Locations, names and velocities of the 11 GPS sites used in the analysis to estimate the Caribbean plate angular velocity relative to the International Terrestrial Reference Frame 2008 (Altamimi et al. 2011). All velocities are relative to ITRF08. The velocity ellipses show the 2 -D, 1-sigma uncertainties. Site names are separated by slashes at locations with more than one closely spaced GPS site. (b) Velocities relative to ITRF08 for all 989 GPS sites used herein to estimate the North America plate angular velocity relative to ITRF08.

Figure S2. New GPS site velocities relative to the North America Plate. Velocities are corrected for coseismic offsets and transient afterslip from the 2009 Swan Islands earthquake and the $2012 \mathrm{El}$ Salvador and southern Guatemala (Champerico) earthquakes (Ellis et al. 2018). Error ellipses are omitted for clarity. GPS site names are printed adjacent to each site and can be viewed upon figure magnification.

Figure S3. 1976-2017 reverse-faulting earthquake focal mechanisms from the global centroid-moment tensor catalogue (Dziewonski et al. 1981; Ekstrom et al. 2012). The black, blue and red arrows, respectively, show velocities that are predicted by the MORVEL Cocos-North America and Cocos-Caribbean angular velocities (DeMets et al. 2010) and our new angular velocity for the Cocos plate relative to the Central America forearc sliver (Table 1 in the main document). Velocities and $1-\sigma$ uncertainties are given in $\mathrm{mm} \mathrm{yr}^{-1}$.

Figure S4. (a) GPS site velocities relative to stationary North America (red) and Caribbean plates (blue). The dark grey areas identify the subduction interface patches that are locked at 25, 50 and 100 per cent of the plate convergence rate for the elastic half-space models whose predictions are shown in (b) and (c). (b) Trenchnormal $\left(\mathrm{N} 32^{\circ} \mathrm{E}\right)$ velocity component versus distance to trench for GPS sites in the Chiapas/western Guatemala transect (red arrows in a). Elastic model predictions use a $78 \mathrm{~mm} \mathrm{yr}^{-1}$ Cocos-North America convergence rate (Fig. S3). (c) Trench-normal $\left(\mathrm{N} 22^{\circ} \mathrm{E}\right)$ velocity component for GPS sites in the El Salvador/Honduras transect (blue arrows in a). Elastic model predictions use a $75 \mathrm{~mm} \mathrm{yr}^{-1}$ Cocos-forearc sliver convergence rate (Fig. S8). All uncertainties are $1-\sigma$.

Figure S5. Eastern (a) and central (b) Motagua-Polochic fault zone transects showing the observed (red) and modelled (blue) GPS site velocity components rotated onto respective fault-parallel azimuths of $\mathrm{N} 62^{\circ} \mathrm{E}$ and $\mathrm{N} 60.5^{\circ} \mathrm{E}$. See legend in (b) for symbol interpretations. The inset maps identify the GPS sites in each transect and their velocities. Uncertainties are $1-\sigma$. The TDEFNODE estimates are for our preferred model. The grey curves show predictions from an elastic half-space model that assumes 100 per cent locking of the Motagua fault to a depth of $15 \mathrm{~km}$. The North American plate is stationary. Abbreviations: cGPS, continuous GPS; eGPS, episodic GPS.

Figure S6. Transects of the Motagua-Polochic fault zone at $90.2^{\circ} \mathrm{W}$ (A) and of the western Polochic Fault (B) with the observed (red) and modelled (blue) GPS site velocity components rotated onto $\mathrm{N} 89^{\circ} \mathrm{E}$ (A) and $S 87^{\circ} \mathrm{E}(\mathrm{B})$, parallel to the Polochic Fault within each transect. The TDEFNODE model estimates are for our preferred model. The inset maps identify the GPS sites and their velocities for each transect, with velocities displayed relative to the North American plate. Uncertainties are 1- $\sigma$. Abbreviations: cGPS, continuous GPS; eGPS, episodic GPS.

Figure S7. Central America volcanic arc transects showing GPS site velocity components locally parallel to the volcanic arc. Inset maps show transect sites and velocities relative to the Caribbean plate. See legend for symbol interpretations. The TDEFNODE estimate is for our preferred model. Uncertainties are 1- $\sigma$. Grey curves show elastic half-space predictions for strike-slip faults fully locked to depths of 5 and $15 \mathrm{~km}$. Abbreviations: cGPS, continuous GPS; eGPS, episodic GPS.

Figure S8. Central America volcanic arc transects showing GPS site velocity components locally parallel to a fault or to the volcanic arc. Inset maps show transect sites and velocities relative to the Caribbean plate. See legend in (a) for symbol interpretations. The TDEFNODE estimate is for our preferred model. Uncertainties are 1- $\sigma$. Abbreviations: cGPS, continuous GPS; eGPS, episodic GPS. 
Figure S9. Oblique Mercator projection of western Central America centred on $7.3^{\circ} \mathrm{N}, 91.4^{\circ} \mathrm{W}$, the pole that best fits the directions measured for 33 GPS sites on the Central America forearc sliver (red velocity arrows) relative to the Caribbean plate. The limits of the Central America forearc sliver are depicted by the light-blue shaded region. The seven GPS sites whose directions are used to determine the pole of rotation for the Gulf of Fonseca block are coloured magenta.

Figure S10. Summary map of residual GPS site velocities for the preferred TDEFNODE inversion (see the text). Residual velocities are the modelled velocities subtracted from the observed velocities. Shading identifies the blocks used for our preferred model. Uncertainty ellipses are 2-D, $1-\sigma$.

Figure S11. Influence of modelling assumptions on the estimated interseismic locking and model fit, as given by reduced chi-square (2 ). (a) Preferred model results, which restrict subduction locking to depths above $40 \mathrm{~km}$, exclude the Chiapas block, and use the Slab 1.0 interface geometry of Hayes et al. (2012). (b) Same as (a), but for a model with a separate, deforming Chiapas block. (c) Weaklocking end-member model described in the text. (d) Same as (a), but for a model without any constraints on slip direction along the volcanic arc in Nicaragua (see the text). (e) Same as (a), but for a model with a more curved subduction interface (see the text). (f) Same as (a), but for model with subduction locking down to $60 \mathrm{~km}$. Figure S12. Estimates of fault slip rate and block strain rates for alternative TDEFNODE models C and D from Fig. S10 (shown in $\mathrm{a}$ and $\mathrm{b}$, respectively). The model in (a) is the minimum-locking end-member model described in the text. The model in (b) excludes any constraints on the relative slip direction along the Nicaraguan volcanic arc. The slip rates estimated at the strike-slip fault nodes are colour-coded according to the scale on the map. The red arrows and their adjacent numbers show the velocities estimated for the plate or block on which each arrow originates relative to the plate or block across the adjacent strike-slip fault. Slip rates have units of $\mathrm{mm} \mathrm{yr}^{-1}$. If available, published geologic fault slip rates are given parenthetically. The grey double-headed arrows show the estimated strain-rate axes, with outward-pointing arrows indicating extensional strain rates.

Figure S13. Estimates of fault slip rate and block strain rates for alternative TDEFNODE models B and F from Fig. S10 (shown in a and $b$, respectively). The model in (a) includes a deforming, Chiapas block in the block configuration. The model in (b) permits locking of the subduction interface to extend downwards to $60 \mathrm{~km}, 20 \mathrm{~km}$ deeper than our preferred model. The slip rates estimated at the strike-slip fault nodes are colour-coded according to the scale on the map. The red arrows and their adjacent numbers show the velocities estimated for the plate or block on which each arrow originates relative to the plate or block across the adjacent strikeslip fault. Slip rates have units of $\mathrm{mm} \mathrm{yr}^{-1}$. If available, published geologic fault slip rates are given parenthetically. The grey double-headed arrows show the estimated strain-rate axes, with outward-pointing arrows indicating extensional strain rates.

Please note: Oxford University Press is not responsible for the content or functionality of any supporting materials supplied by the authors. Any queries (other than missing material) should be directed to the corresponding author for the paper. 